\title{
Das Buch Esther bei den LXX.
}

Von B. Jacob.

Die hellenistische Bibelübersetzung der LXX verlangt und verdient, auch wenn sie nicht unter dem Gesichtspunkt eines textkritischen Mittels betrachtet wird, als ein immerhin bedeutsames literarisches Erzeugnis eine selbstständige Durchforschung und Klarlegung aller äufseren und inneren Beziehungen, Kritik des Textes, Ermittelung des hermeneutischen Characters und sprachlichen Gepräges, von Ort und Zeit der Abfassung, von etwaigen Weiterbildungen, deren Ursprüngen und fernerem Verlauf.

$\mathrm{Zu}$ einer solchen Untersuchung eignet sich in mehrfacher Beziehung das Buch Esther bei den LXX, weil bei kaum einem andern der Reichtum dieser Beziehungen ein so grofser ist. Für die Herstellung seines Textes ist ein reiches Material vorhanden; der Character der Uebersetzung ist trotz des geringen Umfanges derselben ein so ausgeprägter, dafs wir ihn mit hinreichender Deutlichkeit zeichnen können; für seine äufsere Geschichte : Entstehung, Verfasser und Vaterland haben wir Nachrichten, die bei jedem andern auch nichtkanonischen Buche aufser dem Buche der Weisheit des Jesus Sirach vermifst werden und sicherere Merkmale enthält es selbst; für die innere Geschichte und Entwicklung des Buches zeugen kleinere und umfangreichere, mit der eigentlichen Erzählung organisch verbundene Zusätze, die einen nicht unerheblichen Beitrag zur Erkenntnis der apokryphischen Literatur liefern. Nach diesen verschiedenen Richtungen hin soll im Folgenden das Buch Esther untersucht werden, ohne dafs jedoch die Untersuchung, besonders was die Kritik des Textes angeht, erschöpfend sein könnte oder wollte. 


\section{I.}

\section{Der Text des kanonischen Buches.}

Um die Herstellung des Textes haben sich, abgesehen von den Herausgebern des Textes der ganzen LXX besonders bemüht : Jacob Ussher ${ }^{1}$ ), O. F. Fritzsche ${ }^{2}$ ) und de Lagarde ${ }^{3}$ ).

Ussher hat die beiden Texte des cod. Arundelianus (späterhin bei Holmes-Parsons 93) S. 111-156 gegenübergestellt. Jedoch ist er mit grofser Freiheit vorgegangen nicht blos in der Ausfüllung von Lücken, sondern er hat auch die Asterisken fast alle, die Obelen mit den Metobelen durchweg aus eigener Machtvollkommenheit gesetzt. So bezeugt es Holmes, der den Arund. mit Ussher's Ausgabe selbst verglichen hat (Praef. ad Esther), und Field im monitum in librum Esther im ersten Bande der Hexapla S. 792 bestätigt es.

F's Ausgabe beruht ganz auf dem von Holmes-Parsons im dritten Bande ihres Riesenwerks gegebenen textkritischen Stoff, von dem er, wie der Titel besagt, nur eine Auswahl giebt. Jedoch konnte er bereits den zwei Jahre vorher von Tischendorf herausgegebenen Friderico-Augustanus, den er mit $X$ bezeichnet, hinzunehmen. Auch Fr. stellt dem Vulgärtext, den er $\mathbf{A}$ nennt, den andern, B, aus 19, 93a, 108 b Seite für Seite gegenüber. Diese Ausgabe ist dann um der Zusätze willen wiederholt worden in : libri apocryphi veteris testamenti graece Lips. 1871. XI. XII u. $30-72$.

1) in de Graeca LXX interpretum versione syntagma cum libri Estherae editione Origenica et vetere Graeca altera ex Arundeliana bibliotheca Londini 1653.

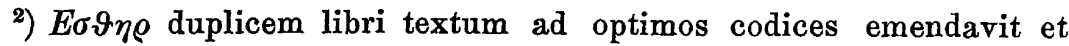
cum selecta lectionis varietate edidit Turici 1848.

3) librorum veteris testamenti canonicorum pars prior. Gott. 1883. 
de Lagarde hat seinem Vorsatze gemäls dort, wo er in den Handschriften der Lucian-Recension einen andern Text vorfand, auch diesen zu geben, S. 504-541 beide Texte gegenübergestellt und nennt den Luciantext $\alpha$, den andern $\beta$. Diese Ausgabe ist um so wertvoller, als unserm Buche allein ein textkritischer Apparat beigegeben ist und zwar für $\beta$ eine mit peinlichster Sorgfalt ausgeführte Collation des Alexandrinus (A), Vaticanus (B) und Friderico-Augustanus (S(inacticus)).

Ueber das Verhältnis der beiden Texte zu einander hat Langen in der Theol. Quartalschrift 1860 geschrieben, ohne indessen die Sachlage zu erkennen, wie dies später von Field und de Lagarde geschah.

Die genannten drei codd. sind natürlich die Grundlage jedes Septuagintatextes, daneben müssen jedoch auch die andern Handschriften geprüft werden, so wenig sie freilich jenen gegenüber ins Gewicht fallen. Von höchster Wichtigkeit ist die altlateinische Uebersetzung, die Vetus Latina. Von syrischen Uebersetzungen steht die Peschittha, was man bei der Lage in andern Büchern nicht erwarten sollte, in gar keiner Beziehung zur LXX. Sie ist eine treue Uebersetzung des hebräischen Textes mit ganz unwesentlichen Abweichungen, in denen sie jedoch nicht mit der LXX übereinstimmt. Eine etwaige syrohexaplarische Uebersetzung scheint, soweit dies zu übersehen war, noch nicht edirt zu sein. Andere Uebersetzungen, wie die äthiopische, armenische, waren dem Verfasser nicht zugänglich oder nicht verständlich. Die Recension Lucians oder vielmehr die darunter liegende Schicht echten Septuagintaguts ist der nächste Zeuge. Der Bericht des Josephus kann in manchen Fällen sehr hoch hinaufführen. Das Mittel, diese Zeugen zu prüfen, bleibt natürlich beständig der hebräische Grundtext. Für seine methodische Benutzung zur Herstellung des griechischen Textes kann auf die bekannten Grundsätze de Lagarde's (Anmerkungen 
zur griechischen Uebersetzung der Proverbien Lpz. 1863, S. 3) verwiesen werden. Doch bleibt auch hier als Malsstab zuletzt nur die Kenntnis von dem Stil des Uebersetzers. Besonders ist bei der Freiheit unserer Uebersetzung die fehlende Uebertragung eines hebräischen Wortes, Verstheils oder Verses durchaus noch kein Beweis für einen Ausfall. Erst wenn von andrer Seite eine Lücke glaubhaft bezeugt wird, kann sie durch das Hebräische bestätigt werden.

\section{Die Handschriften.}

Aufser in jenen drei berühmten Handschriften aus dem vierten und fünften Jahrhundert ist der Vulgärtext des Buches Esther noch in einem Unzial und sechszehn Minuscelcodices erhalten, von denen Parsons die Varianten mitteilt. Aufserdem verzeichnet P. die Lesarten der Complutensis und Aldina.

Diese Handschriften und Ausgaben nun ordnet Fritzsche : $\boldsymbol{E} \sigma \vartheta \eta \rho$ dupl. text. 4 in drei Klassen :

1. ABS XI. 55. 93 b. 108 a. 249.

2. 64. 243. 248. Co. Ald. 52.

. 3. 44. 68. 71. 74. 76. 106. 107. 120. 236.

Bei einer nochmaligen Prüfung heben sich aus der verwirrenden Fülle des Stoffs für die von de Lagarde nicht verglichenen Handschriften folgende Thatsachen heraus :

44 und 106 (107) gehören zusammen und sind aus einem und demselben Exemplar abgeschrieben, denn sie gehen von Anfang bis Ende zusammen und haben gemeinsame Schäden. So dieselben durch Homöoteleuton veranlalsten Lücken :

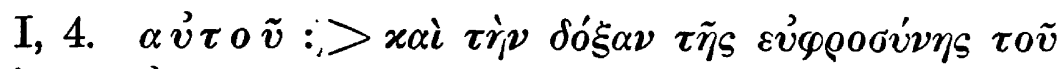
$\pi \lambda o v i \tau o v \alpha \dot{v} \tau o \tilde{v}$.



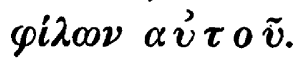




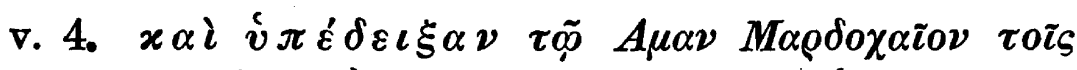

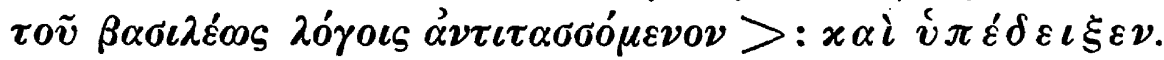

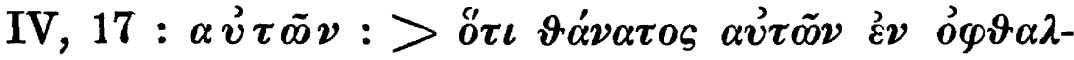
$\mu o \iota_{\varsigma} \alpha \hat{v} \tau \tilde{\omega} \nu$.

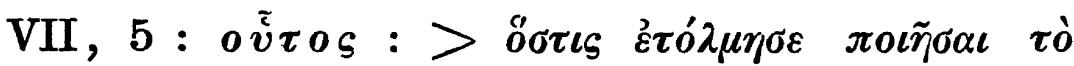
$\pi \rho \tilde{\alpha} \gamma \mu \alpha \tau \boldsymbol{\tau} \tilde{\boldsymbol{v}} \boldsymbol{\tau}$.

Andere Lücken sind I, 8. 12. II, 5. 15. Grofse Lücken im Gebet Esthers, VI, 2. 7. XI, 1. 4. 16. 26 (zwei Zeilen), v. 28 ganz. Hierzu treten, was, wenn möglich, noch beweisender ist, gemeinschaftliche Aenderungen : In add. I. wird der Ausfall von "ैy

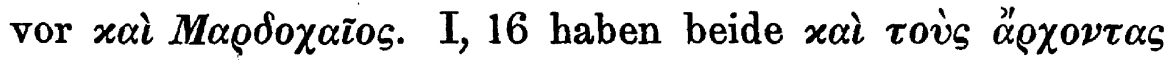

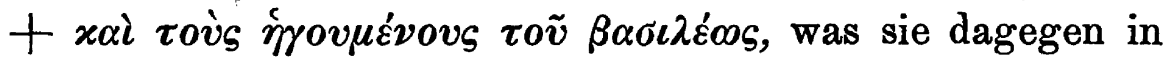
der nächsten Zeile auslassen. I, 21 für $x \alpha \vartheta \dot{\alpha} \varepsilon \varepsilon^{2} \alpha \alpha^{\prime} \lambda \eta \sigma \varepsilon v$ ó

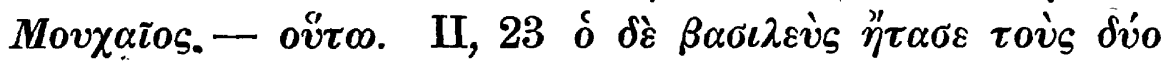



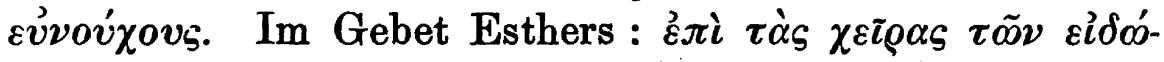

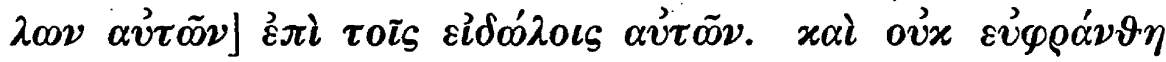

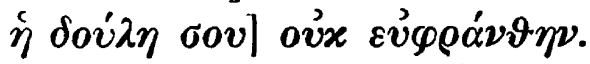

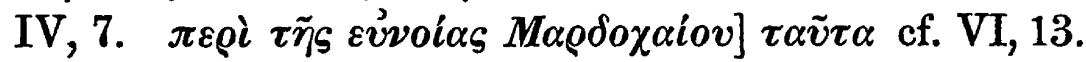

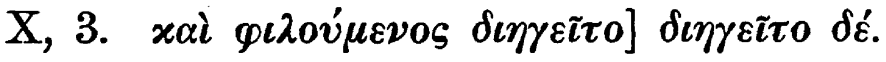

$\mathrm{Da}$ in allen diesen und vielen andern unwesentlicheren Fällen diese beiden Handschriften gegen alle andern, auch ihre nächsten Verwandten, stehen, so müssen sie aus derselben Quelle geflossen sein. Es kann aber der spätere Zittaviensis 44 nicht aus 106 abgeschrieben sein, denn innerhalb der durch die obigen Anführungen gekennzeichneten Grenzen geht wiederum jeder von ihnen seine eigenen Wege und leistet: besonders in Auslassungen das mögliche. So fehlen in 106 vom achten Kapitel v. 3. 6, vom neunten v. 14. 18. 31. 32 , während 44 die letzten drei Verse dieses Kapitels in die Worte zusammenfalst. $x \alpha i$ "’

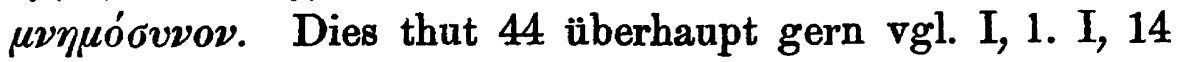
u. ö. Sonstige Beispiele ihrer selbständigen Fehlerhaftig- 
keit giebt jedes Kapitel in Menge. Erwähnt sei noch,

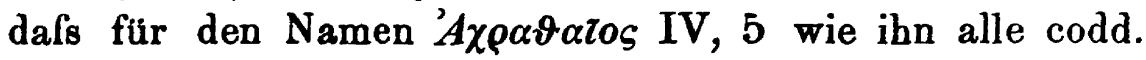
schreiben mit Ausnahme von $\mathbf{A S}^{1}$, welche 'A $\chi \vartheta \rho \alpha \vartheta \alpha i$ os haben, nur unsere beiden eine abweichende Form geben

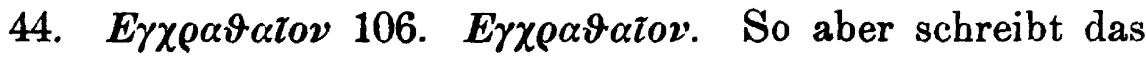
Onomasticon bei de Lagarde: Onomastica sacra I 164. 69.

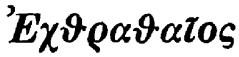

Ebenso eng wie 44. 106 gehören 74. 76 zusammen. Diese beiden verlassen sich fast nie. Abgesehen von sonstigen Uebereinstimmungen, in denen sie Genossen haben,


$\rho \varepsilon \sigma x \alpha \iota \delta \varepsilon x \alpha \dot{\tau} \eta]+\tau 0 \tilde{v} A \delta \alpha \rho$.

Ebenso schliefsen sich aneinander 120.236, von denen sich der letztere durch häufige Verschreibungen, Auslassungen als der schlechtere ausweist, ohne dafs jedoch diese beiden Paare wie 44. 106 Eigentümlichkeiten hätten, die sie auffallend von andern trennten. Der schlechteste Codex von allen dürfte 71 sein. Er schaltet am freiesten mit dem Text und hat besonders die Zusätze bedeutend, aber nicht, wie Parsons meinte, ohne Ueberlegung gekürrt. So ist das Gebet Mardechai's von dreizehn Zeilen bei Holmes in drei zusammengezogen. Im Gebet Esther's fehlen neun Zeilen, um aber den Zusammenhang herzustellen,

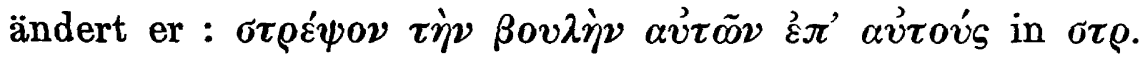

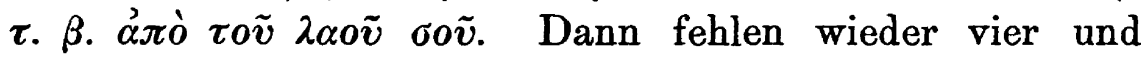
abermals drei Zeilen. Auch im zweiten Edikt fehlen wieder etwa sechs Zeilen. Sonst fehlen an ganzen Versen : III, 14. IV, 3. IX, 20. 21. 22. 26. 32. Trotzdem ist das neunte Kapitel bei ihm im Zusammenhang. Auch sonst hat er unzählige kleinere und gröfsere Lücken. Unglaublich aber ist die Willkür, mit der er ändert, umstellt, kürzt

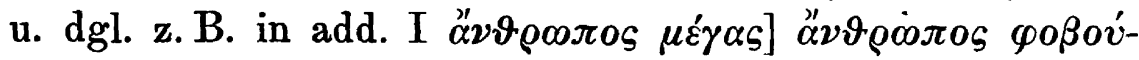

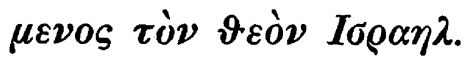

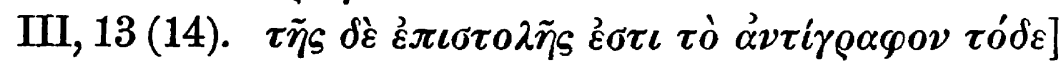

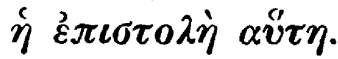




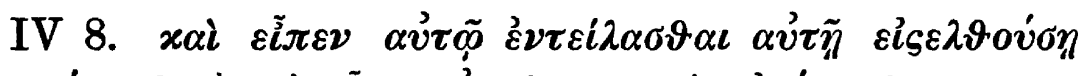

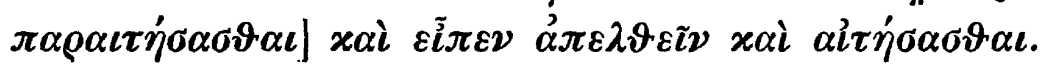

Dafs aber alle diese bisher genannten codd. zusammengehören, zeigen, aufser unzähligen andern, Stellen wie folgende :

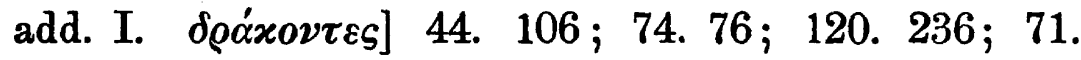
$+\stackrel{\varepsilon}{\pi i} \tau \tilde{\eta} s \gamma \tilde{\eta} s$.

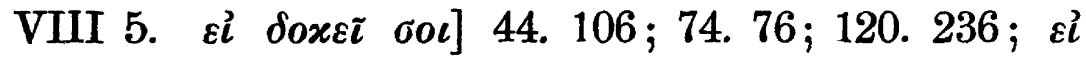

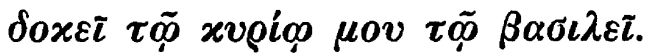

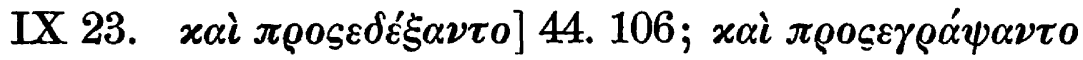
74. $76 ; 71.236$.

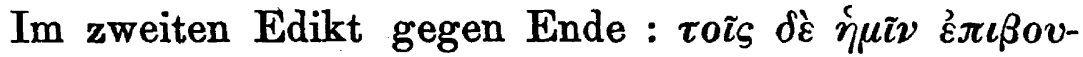

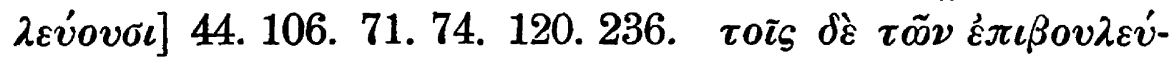

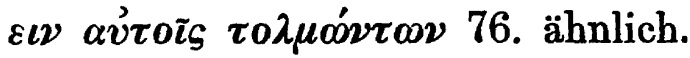

Alle diese codd. gehören daher, wie es scheint, einer Familie an, deren Verhältnisse folgendes Stemma, natürlich nur annähernd, veranschaulichen könnte :



Dafs R eine Majuskelhandschrift gewesen sei, dafür spricht nichts, wohl aber lassen manche Anzeichen wie die häufigen Verwechselungen von $x \alpha i$ und $x \alpha \tau \dot{\alpha}$, von $\pi \rho o ́ s$, $\pi \alpha \varrho \alpha-, \pi \varepsilon \rho-$ oder $\dot{\alpha} \pi 0-, \hat{v} \pi 0_{-}, \vec{\varepsilon} \pi \iota-$ und die vielen Fehler und Verschreibungen in Verbal- und Nominalendungen auf einen mit zahlreichen Abbreviaturen geschriebenen Minuskelcodex schliefsen.

Von den andern codd. läfst sich aus unserem Buche allein nur sehr weniges feststellen.

Wenn derjenige Codex der beste oder doch die beste Abschrift von B ist, der am seltensten im kritischen Ap- 
parat genannt wird, so dürfte dies von 55 gelten, denn diesem begegnen wir von unwesentlichen Verschreibungen abgesehen, verhältnifsmäfsig selten. Aufserdem spricht einigermafsen für ihn, dafs er augenscheinlich aus einem Majuskel-

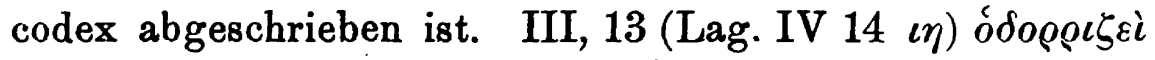



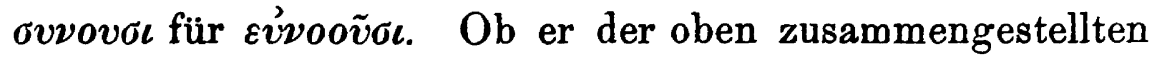
Familie zuzuweisen ist, läfst sich nicht bestimmen, denn er geht ebenso oft in seinen kleinen Abweichungen mit einer andern Gruppe; wobei jedoch wieder bemerkenswert ist, dafs er nicht die Interpolation VII, 9. hat.

Einer der eigenwilligsten Handschriften ist 249. Dafs er zunächst hexaplarisch beeinflufst ist, gibt Parsons im allgemeinen von ihm an, und für unser Buch beweisen dies mehrere Zusätze, die sich auch in $93 \mathrm{~b}$ finden und dort

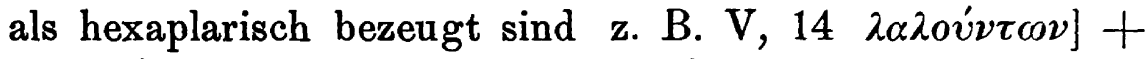
$\mu \varepsilon \tau^{\prime} \alpha v^{\prime} \tau \tilde{v}$. VII, $\left.9 \lambda \alpha \lambda \eta^{\prime} \sigma \alpha \nu \tau \iota\right]+\alpha^{\prime} \gamma \alpha \vartheta \dot{\alpha}$. VIII, $1 A \mu \alpha v \tau \tilde{\varphi}$

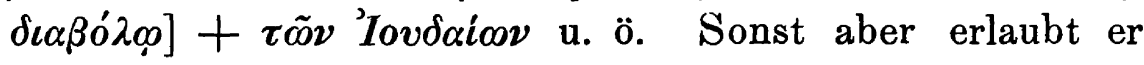
sich die gröfsten Willkürlichkeiten in Aenderungen, Umstellungen u. s. w. III, $6 \beta \alpha \sigma \iota \lambda \varepsilon i \alpha \nu]$ $\alpha \varrho \chi \dot{\eta} \nu$, VI, $10 \tau \tilde{q} \vartheta \varepsilon \rho \alpha-$

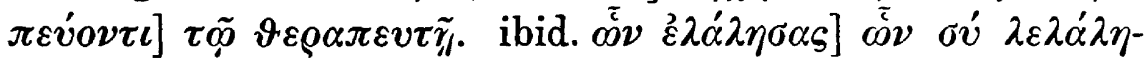
xaৎ und so sehr häufig. Jedoch auch wenn bereits sein Stammcodex diese Fehler beging, so mufs er einer der besseren gewesen sein, denn er wird dann selten genannt, wenn es sich um andere als offenbar selbstgemachte Varianten handelt. Bei dem ersichtlich eklektischen Verfahren aller dieser Handschriften ist es hier ebenso mifslich wie bei 55 ihn als Mitglied einer bestimmten Familie reclamiren zu wollen.

Dafs die Complutensis ein getreuer Abdruck von 248 sei, ist längst bekannt und aus unserm Buche liefert fast jeder Vers den Beweis dafür. An Fällen, in denen nur diese beiden eine von allen andern abweichende Lesart haben, führen wir z. B. V, 1 an $\tau o \tilde{v} \pi \varepsilon \dot{v} \vartheta o v \varsigma$ für $\tau \tilde{\eta} \varsigma$

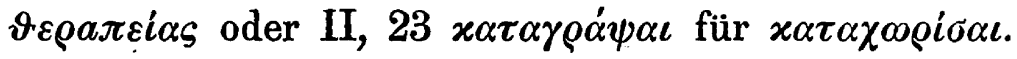


Mit diesen bəiden nun gehen in den meisten Fällen 243. Ald. 52. 64. Wie sie zusammengehören, zeigt z. B. eine Interpolation, welche nur diese Gruppe hat, ohne dafs man leider bei Parsons sehen kann, ob sie im Text oder am Rande steht.

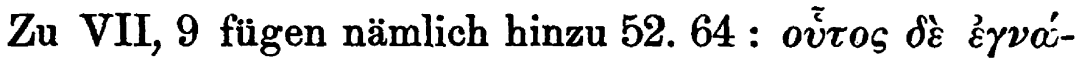



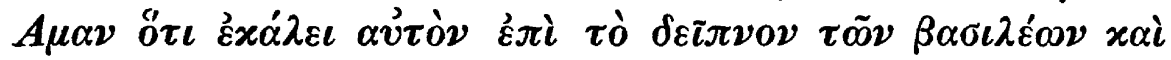

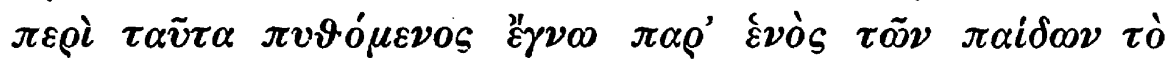

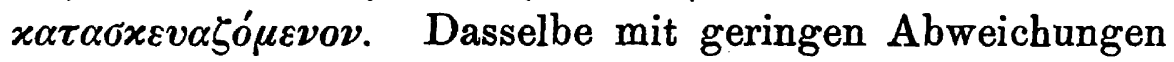
243. 248 Compl. Ald.

Diese Interpolation aber stammt offenbar aus Josephus

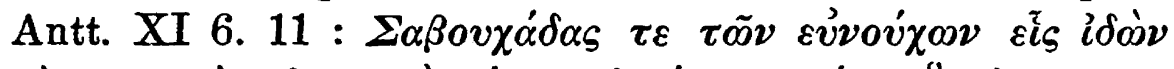

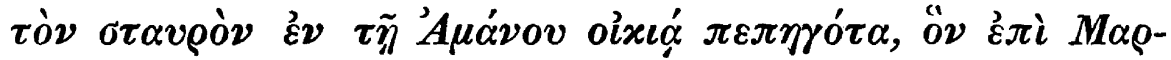

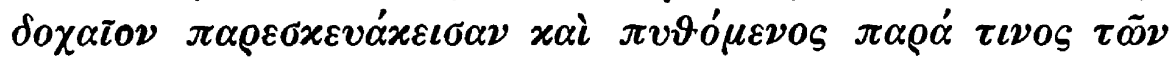

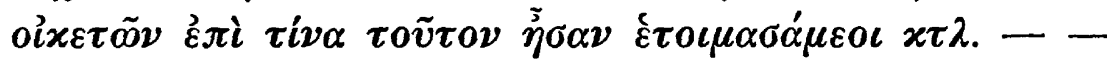

Dies ist alles, was sich mit einiger Sicherheit aus dem Wust von Varianten herausheben läfst, und man sieht, das Resultat ist im wesentlichen das von Fritzsche gefundene; aber da Fritzsche die Gründe seiner Einteilung nicht angiebt, schien es einerseits der Mühe wert, dasselbe in einzelnen Punkten näher zu begründen, wie andrerseits das gesagte das Urteil rechtfertigen kann, dafs diese Handschriften allesamt nichts wert sind. Spät geschrieben und willkürlich mit dem Text verfahrend, dürfen sie ABS gegenüber gar nicht in Betracht kommen.

\section{Die Vetus Latina.}

Nach der allgemeinen Annahme ist die alte lateinische Uebersetzung der LXX um die Mitte des zweiten nachchristlichen Jahrhunderts entstanden. Die Hauptstreitpunkte in dieser schwierigen Frage sind zumeist die Entscheidungen über Einheit und Vaterland der Uebersetzung. Hier kann es sich nur darum handeln, inwieweit die erhaltenen Reste einer altlateinischen Bibelübersetzung zur 
Herstellung und Verbesserung des LXX-Textes verwendet werden können. Vorweg sei bemerkt, dafs sowohl die Kirchenväter als die Vulgata ausscheiden. Von jenen fuhrt wenigstens Sabatier zum kanonischen Text des Buches Esther keine Zitate an und Hieronymus hat das Buch ohne Rücksicht sowohl auf die früheren lateinischen Uebersetzungen wie auf die LXX unmittelbar aus dem Hebräischen übertragen. Doch scheint er sich an manchen Stellen bei andern Uebersetzern Rats erholt zu haben z. B. I, 6 bei Aquila.

Für unser Buch nun fliefst die Quelle besonders reichlich; denn die V. L. zu Esther ist zweimal in drei Handschriften vollständig erhalten.

Sabatier hat in seinen Bibliorum sacrorum latinae versiones antiquae Paris 1741 folgende drei codd. benutzen können.

C. Corbeiensis 7.

O. Oratorius B. VII. enthält add I. cap. I. II.

P. Pechianus, dieser beginnt grade dort, wo $O$ aufhört und reicht bis ans Ende des Buches. Aufserdem führt Ziegler : die lateinischen Bibelübersetzungen vor Hieronymus und die Itala des Augustinus, München 1879 S. 106 mehrere unedierte Handschriften an, so einen vollständigen altlateinischen Text des Buches Esther in cod. lat. Monac. 6239 saec. IX von fol. $86 \mathrm{~b}$ an. Im folgenden konnte nur das Material Sabatier's behandelt werden.

Ueber den Charakter der Uebersetzung spricht S.'s Autorität das Urteil: Vix ulla magis antiquam versionem sapit seu ut aiunt Italicam. Sie ist weit sclavischer als die griechische und übersetzt Wort für Wort ihrer Vorlage fast gänzlich unbekümmert um den. Sinn. Besonders zeigt sich dies bei der Uebertragung der beiden Edikte, deren schwieriger Diction der Uebersetzer durchaus nicht gewachsen war, die daher bei ihm ganz unverständlich sind. Oft erkennt man nur noch die Trümmer der 
griechischen Worte. Nun könnte ja für unsern Zweck nichts erwünschter sein, als wenn eben der Lateiner so wörtlich und sclavisch wie möglich übersetzte. Wir brauchten ihn dann nur mit Vorsicht und beständiger Vergleichung des griechischen Handschriftentextes zurückzuübersetzen, um die älteste vorläufig erreichbare Gestalt des Textes zu gewinnen. Leider aber geht dies nicht an. Denn der Text der V. L. ist in solcher Verwirrung, schon so vielfältig glossiert, die je beiden Handschriften weichen so stark von einander ab, dafs Fritzsche diesen wichtigsten aller Zeugen, der als einzige vorhexaplarische Uebersetzung selbst ABS noch übertreffen könnte, sublestae fidei nennt und fast gar nicht berücksicht.

Geringere Varianten, die in den LXX-Handschriften schon bedeutende Abweichungen wären, giebt es in fast jedem Verse. Einige Proben, an denen man zugleich Entstehung und Tendenz der Abweichungen erkennen kann, mögen genügen $\mathrm{I}, \mathrm{C}$ : in diebus Artaxerxis $\mathrm{O}$ : in diebus regis Art. C: ab India $\mathrm{O}$ : in Asia v. 6. C : derpina $\mathrm{O}$. dispna $\mathrm{C}$ : byssina et hyacynctina et super organa extenta $\mathrm{O}$ : sacchina organa extenta $\mathrm{C}$ columna eparina (sic. Gr \#a@ívoss) $\mathrm{O}$ columnae variae viperniniae. $\mathrm{C}$ : super lapides marmoratos $\mathrm{O}$ : super lapidem marmorati strati. 11. $\mathrm{C}$ : ut inducerent reginam ad eum $O:$ ut inducerent ad se reginam. $C$ formosa enim erat $O$ : quoniam formosa erat. 12. $\mathrm{C}$ : et noluit $\mathrm{O}$ : et non obedivit. II, $7 \mathrm{C}$ : sicut adoptatam filiam 0: sibi in filiam u. s. w. So geht es durch die ganzen beiden Capitel, für die $O$ erhalten ist. Diese Verschiedenheiten sind so stark, dafs man sich vor die Frage gestellt sieht, ob man es nur mit Varianten einer Uebersetzung oder mit zwei ganz verschiedenen Uebersetzungen zu thun hat. Dafs überhaupt mehrere verschiedene Uebersetzungen des Buches Esther zur Zeit des Hieronymus vorhanden waren, glaubt Ziegler a. a. $O$. als sicher an- 
nehmen zu können aus den einleitenden Worten der praef. in Esther : librum Esther variis translatoribus constat esse vitiatum. Aber diese Worte dürften sich eher auf die LXX beziehen, denn nur mit ihrer Verderbtheit kann er sein Zurückgehen auf den Grundtext gerechtfertigt wissen wollen. Ein entstellter lateinischer Text hätte ihn zunächst nur an die LXX verwiesen. Aber auch wenn die Deutung Ziegler's die richtige ist, so ist damit natürlich noch nicht gesagt, dafs gerade unsere codd. die verschiedenen Uebersetzungen bieten. Vielmehr glauben wir, dals eben die angeführten Beispiele - die sich deutlich als Verderbnis oder Correctur zu erkennen geben, zu der Annahme berechtigen, dafs hier nur eine Uebersetzung zu grunde liegt. Manches kann allerdings aus einer gemeinsamen fehlerhaften Vorlage hergeleitet werden z. B. dafs II 7 beide die Teile des Verses umstellen oder I 14 gedankenlos


worin man $\pi \varrho o x \varepsilon i \mu \varepsilon \nu o \nu(!)$ erkennt. Anderes ist aber nur als von einem Uebersetzer herrührend zu begreifen. I 3.4 fehlen in beiden Handschriften; v. 5. C : fecit potum his qui erant inventi. $O$ : in anno duodecimo regni sui fecit potum etc. Hier liegt offenbar folgendes Versehen vor :

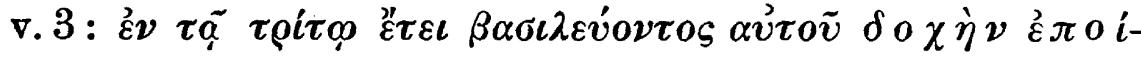

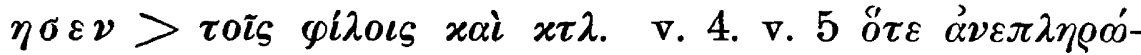

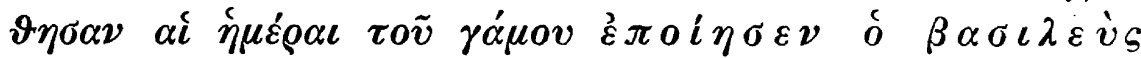
$\pi \dot{\boldsymbol{\tau}} \boldsymbol{0 \nu}$. Ein ähnliches Beispiel ist II 13. CO : et tunc

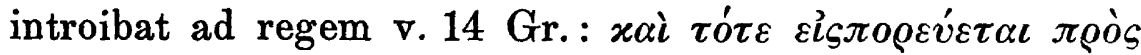

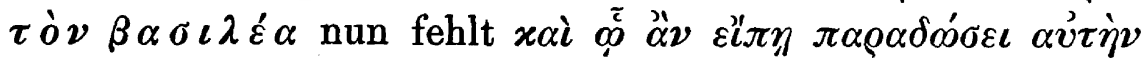

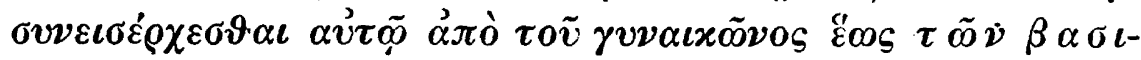
$\lambda \varepsilon i \omega \nu$.

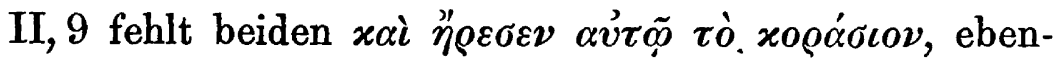
dort haben beide de domo eiusdem aetatis ipsius Gr.

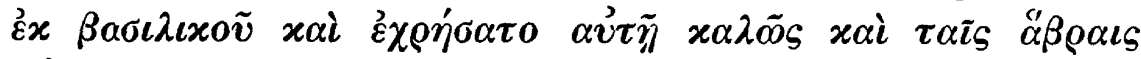
$\alpha \hat{v} \tau \tilde{\eta} s$. In dem Lateinischen erkennt man nur noch olıxov aus $\beta \alpha \sigma \iota \lambda \iota x o \tilde{v}$, aetatis scheint aus einer Corruption von 


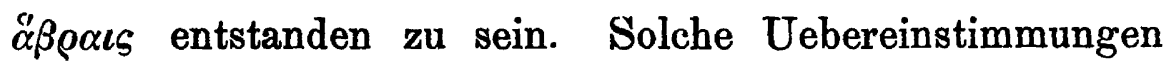
sind doch wohl nur zu erklären, wenn man nur eine Uebersetzung annimmt. Wenn II, $14 \mathrm{C}$ schreibt ad diem unum et recurrebat in muliebre secundo, dagegen $O:$ ac die una recurrebat in atrium muliebre secundo die, so kann dies nur eine Verbesserung von $\mathrm{C}$ sein sollen. Hätte er den griechischen Text vor sich gehabt, so hätte er nicht $\delta \varepsilon \dot{v} \tau \varepsilon \rho o \nu$ mit secundo die übersetzen können; dagegen konnte er leicht secundo mifsverstehen. So schreibt er II, 10 für indicaret : renuntiaret v. 12. impletum : adimpletum v. 13. cum advenisset : cum expletum esset, invenerant eam : intuebantur eam. Jedoch hat er uns einen vollständigeren Text erhalten, denn $\mathrm{C}$ hat mehrere Lücken, so I, 15. II, 1. 2. 3.

Von c. III ab tritt für $\mathrm{O}$ cod. $\mathrm{P}$ ein. Zunächst haben beide bedeutende Lücken. Es fehlen im Gebet Mardechai's v. 10. 11. Gebet Esthers v. 6-12. IV, 1-3. V, 6-8. IX, 1. 2. 5-19. 24-26. 30-32. X, 1. Dazu in $\mathrm{P}$ im ersten Edikt v. 2. 3. 5. 14. IV, 12-14. 15 halb, im Gebet Mard. 15-17, im Gebet Est. 5. 14. 15. 16. VIII, 12. 13, das ganze in $\mathrm{C}$ ohnedies unverständliche zweite Edikt IX 27-29.

Die Abweichungen sind hier noch bedeutend stärker, nicht nur in Casus, Numerus, Genus und Tempus verbi und Wortstellung, sondern auch in Synonymen.

III, 1. C : praetulit $\mathrm{P}$ : exaltavit 4 indicaverunt $\mathrm{P}$ ostenderunt 5. $\mathrm{C}$ : vehementer $\mathrm{P}$ : valde $\mathrm{IV}, 9 \mathrm{C}$ : voce amara et gravi $\mathrm{P}$ : terribili et grandi 10. C : spadonem P : eunuchum 11. C : liberabitur P salvabitur Gebet M.'s C plantas pedum Aman adorare $\mathrm{P}$ : pedum Aman osculare 14. C : intemperatione $P$ : tentatione Gebet Esther's 2. C :



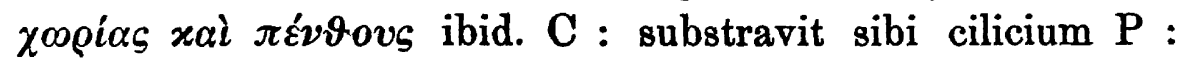
substravit sacco v. 3. C : suffraga $\mathrm{P}$ : in adiutorium esto Gr. $\beta o \eta \dot{\vartheta} \eta \sigma o v$ 4. vestimenta operationis $\mathrm{P}:$ v. curationis 
Gr. $\vartheta \varepsilon \rho \alpha \pi \varepsilon i \alpha s$ 9. sedentem in sedili $\mathrm{P}: \mathrm{s}$. in thronum. V, 11. C epulentiam P : die ältere Form opolentiam VI, 13. $C$ contigerant $\mathrm{P}$ : evenerunt. VII, 2. C : relatio $\mathrm{P}$ : postulatio 8 eam tenens $\mathbf{P}$ et genua illi tenens.

In welchem Verhältnis stehen nun diese beiden Handschriften? Hier scheinen denn doch zwei ganz verschiedene Uebersetzungen jede ihre eigene Sprache zu sprechen. An manchen Stellen scheint es keinen andern Ausweg als diese Annahme zu geben. Wenn z. B. in dem Verse vor E's Gebet C : supervixit P. exlamavit schreibt, so mufs,

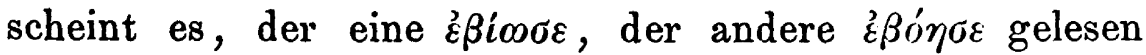
haben. Dennoch hat die gesamte nicht zu bezweifelnde griechische Ueberlieferung $\dot{\varepsilon}^{\prime} x \varepsilon \dot{\varepsilon} x \rho \alpha \xi \varepsilon v$ oder ${ }^{\prime \prime} x \rho \alpha \xi \xi \varepsilon v$.

An andern Stellen kann man kaum eine solche Vermutung fassen. VII 7 hat, was im Gr. fehlt $\mathrm{C}$ : proiciens mappham P : pr. calicem meri. Das eine ist $\dot{\varepsilon} x \mu \alpha \gamma \varepsilon \tilde{\imath} o v$,

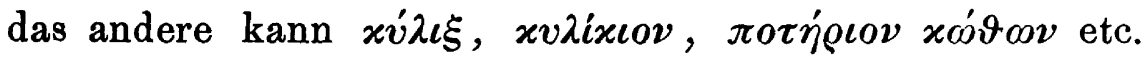
aber kein jenem ähnliches Wort sein. Aber selbrt solch auffallende Einzelheiten, die sich immenhin als glückliche Conjecturen begreifen lassen, dürfen uns nicht davon abbringen, trotz aller Verschiedenheiten in beiden Handschriften nur eine Uebersetzung zu sehen. Denn man bedenke, dafs der Grundstock des Textes beiden gemeinsam ist. Lange Stücke gleichen sich fast völlig und auch in manchen Besonderheiten stimmen sie überein. VI 13 übersetzen beide $\vartheta \varepsilon \dot{o} \varsigma \zeta \tilde{o} v \mu \varepsilon \tau^{\prime} \alpha \dot{v} \tau o \tilde{v}$ mit propheta est IX 22 CP mittere dona et partes sacerdotibus et amicis et pauperibus et orphanis et viduis. Die im Gr. fehlenden Priester, Witwen und Waisen hat offenbar dieselbe geistliche Hand mitbedacht.

Andrerseits lassen sich nicht alle $\dot{F}$ älle, in denen $P$ im Recht ist, durch Annahme einer Conjectur erklären, vielmehr mufs er den Text mit Zuhilfenahme des Griechischen verbessert haben. 


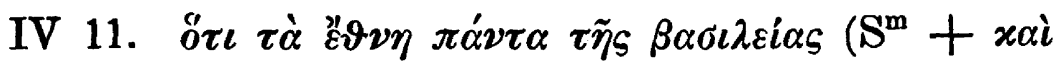

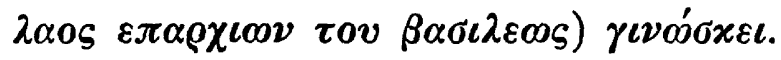

C : quoniam omnis homo omnis gentis Artaxerxes rex $\operatorname{dixit}(!)$

P : quoniam omnis homo et omnes gentes regis Artaxerxis sciunt.

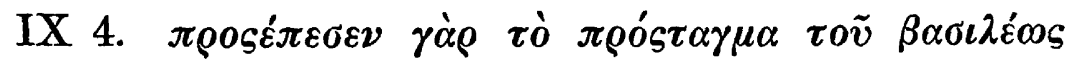
o’vo $\mu \alpha \sigma \vartheta \tilde{\eta} \nu \alpha \iota$.

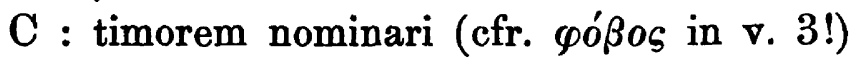

$\mathrm{P}$ : imperium nominari.

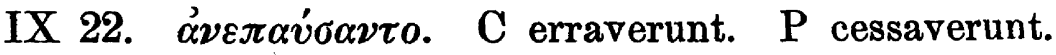

VIII 3 ist in $\mathbf{C}$ ganz verdorben, in $\mathbf{P}$ richtig übersetzt.

Die Erklärung, dafs P ein nach dem Griechischen verbesserter Text sei, ist doch wohl wahrscheinlicher, als die andere Möglichkeit, dafs $\mathrm{P}$ der primäre Text sei, aus dem dann $\mathbf{C}$ verdorben wäre. Es würde schwer sein, hiernach die oft widersinnigen Corruptionen, nachdem einmal das Richtige gegeben war, zu erklären.

Aber der griechische Text, der P vorlag, war nicht unser heutiger Vulgärtext der LXX, sondern ein vielfach abweichender. VI 1.2.3. 10 wird der interpolierte Text Lucians übersetzt.

Diesem folgen an mehreren Stellen beide Handschriften :

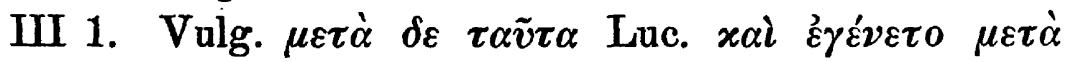

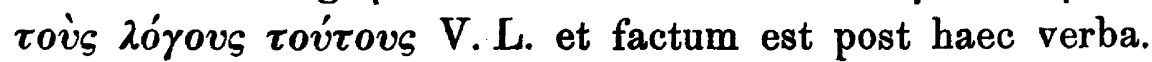


V. L. ficto cordo propter genus Judaeorum.

v. 8. V. L. $=$ Luc.

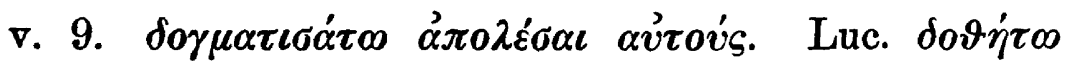

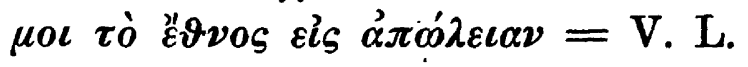

Es ist wahrscheinlicher, - denn mehr als Wahrscheinlichkeit dürfte in dieser Textesverwirrung nicht zu erreichen sein - dafs wir hier Ueberbleibsel der echten LXX, die auch in Lucian's Recension übergegangen sind, vor 
uns haben, als eine Interpolation der V. L. nach Lucian, denn jene Stellen sind entweder freiere Uebersetzungen oder Zusätze, die von der Sprache und ganzen Haltung der lucianischen Recension merklich abweichen.

Schliefslich kann man auch für Esther die Bemerkung machen, dafs V. L. einem dem Alexandrinus nahestehenden Text folgte.

II 1. BS xai ov้x हैं

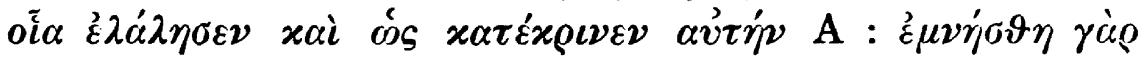

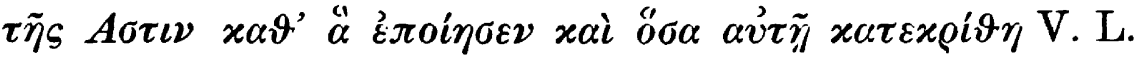
et commemoratus est quae fecit Vasthis et quemadmodum respondit (!)

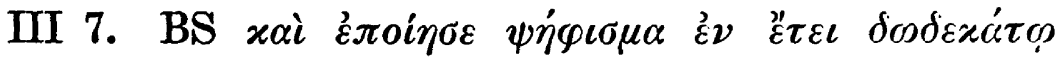

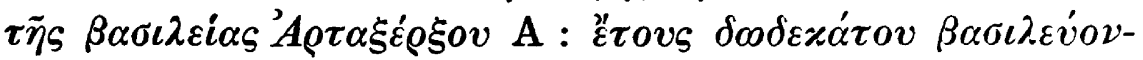





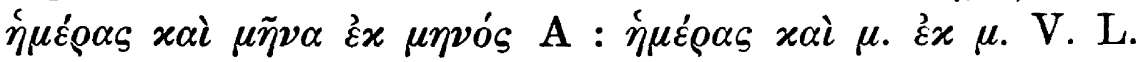
in die et mense ex mense. BS. "̌ $\gamma \rho \alpha \psi \varepsilon v$ A ${ }^{\prime \prime} \gamma \rho \alpha \dot{\varphi} \varphi \eta \sigma \alpha \nu$ V. L. et scripta sunt quae.

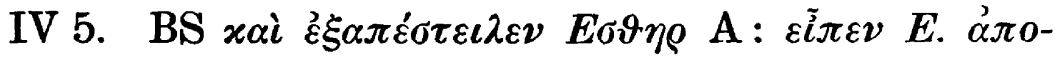
$\sigma \tau \varepsilon \tau \lambda \alpha \iota \pi \dot{\alpha} \lambda \iota v$ V. L. et dixit E. denuo cum misisset.

Innerlateinischen Verderbnissen stehen zahlreiche $\mathrm{Zu}$ sätze zum Griechischen gegenüber, und sie sind, von kleinen Abweichungen abgesehen, beiden Handschriften (CP) gemeinsam. So fügen sie ein kurzes Gebet der Juden hinzu; die Verhandlungen zwischen Esther und Mardechai sind ausführlicher und wortreicher. Dennoch mufs man sich hüten, dies alles als Zuthaten des Lateiners zu bezeichnen, denn man kann wenigstens bei einèm solchen Zusatz mit Bestimmtheit eine Uebersetzung aus dem Griechischen und in dieses aus dem Hebräaischen (oder Aramäischen) nachweisen.

C. IV 16. 17 heifst es in der V. L. :

praedica igitur sanitatem et annuntia ieiunium et dicito presbyteris, ut faciant ieiunium, lactantes autem separent 
nocte a matribus suis, boves et pecora non pascantur, quibus diebus ego et ancilla mea ieiunabimus et introibo ad regem post haec habens in manu mea animam meam. Et exiit spado et dixit verba ejus et vadens Mardochaeus praedicavit sanitatem; sponsi autem de thalamis exierunt et sponsae de pascuis suis ad deprecandum, boves et pecora praecepit, ut tribus diebus et tribus noctibus non pascerentur. Omnes autem acceperunt cinerem etc.

In diesem Stücke sind zwei offenbare Uebersetzungsfehler, von denen der eine nur aus dem Mifsverständnis eines griechischen, der andere eines hebr. (oder aram.) Originals entstanden sein kann. Im Griechischen hiefs es

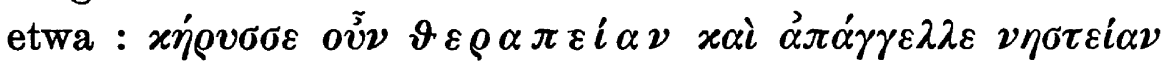

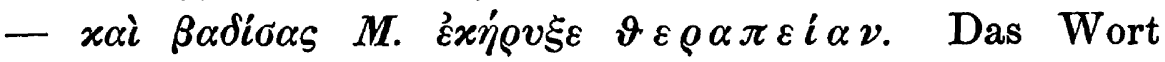


Dagegen ist der andere Fehler : sponsae de pascuis suis

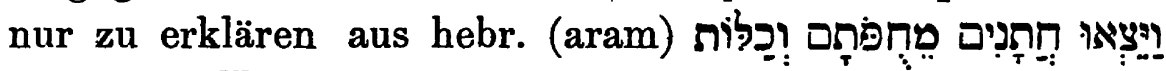

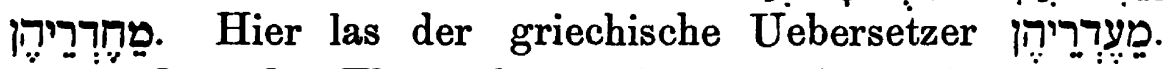
Wenn $\mathrm{P}$ in der That cubiculis hat, so kann dies wieder nur eine glückliche Conjectur sein, denn schwerlich lag ihm der hebräische Text vor. Gebildet ist dieser Zusatz augenscheinlich nach Joel II 15 b. 16 (ähnlich Jona 3, 7). Ueberraschend aber ist es, dafs wir einer ganz ähnlichen Paraphrase bei demselben Verse in Targum U begegnen. In dieses aber ist sie aufgenommen aus einem תרגום רבתי; denn aus einem solchen wird sie zitiert von Salomo Alkabez in seinem umfassenden Commentar zu Esther : מנות הלוי Venedig 1585, in dem überhaupt die gesamte Hagadah zu unserm Buche und viele unbekannte Targumim gesammelt sind. Dort heifst es : ויפוק חתנא מבית משכביה

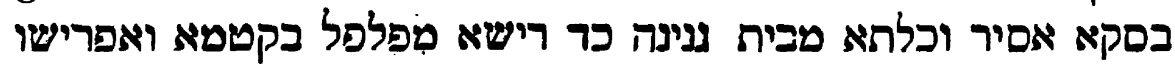

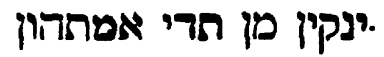

Es ist kaum anzunehmen, dafs eine einzelne Stelle aus der alten lateinischen Uebersetzung der LXX in ein Tar- 
gum versprengt sein sollte. Dann aber hätten wir hier die Spur eines jedenfalls sehr alten Targum zu Esther.

V 9. Reversus est autem Aman a coena et trecenti viri cum eo. VI 4. Vigilavit autem Aman in regia regis et trecenti viri cum eo. Diese dreihundert Mannen Hamans sehen nicht nach einer Erfindung des Lateiners aus, vielmehr nach einem Targum, das wie Targum I oft nur mit einem Wort eine Hagadah andeutet. - -

In solch heilloser Verwirrung nun befindet sich diese Uebersetzung, dafs man an ihrer Benutzung verzweifeln mürste, wenn sie nicht eben sonst mit so sclavischer Treue übersetzte, dafs ihre griechische Vorlage fast stets unschwer zu erkennen ist. Daher mufs dieser Zeuge immer gehört werden.

Jedenfalls aber giebt uns die V. L., wenn wir sie uns ganz ins Griechische zurückübersetzt denken, ein lehrreiches Bild von dem verwahrlosten Zustand, in welchem sich zu jener Zeit der griechische Text an manchen Orten befand, und wie heilsam die Arbeit des Origenes trotz mancher Verwirrung, die sie gestiftet, gewesen ist.

\section{Die Recension Lucians.}

Seitdem von Field (Hexapla LXXXIV ss.) und unabhängig von ihm von de Lagarde festgestellt ist, dafs die codd. 19. 93.108 bei L. h m d neben anderen, die uns nichts angehn, diejenige Recension der LXX darstellen, welche Lucian, Presbyter von Antiochia am Ausgang des dritten Jahrhunderts vornahm und die von Constantinopel bis Antiochia Geltung hatte, seit dieser für die Septuagintaforschung so fruchtbaren, von de Lagarde am 'glücklichsten und energischsten verfolgten Entdeckung kann nicht mehr die Rede davon sein, dafs wir in dem Text jener drei codd. eine zweite Uebersetzung haben, wie Ussher u. a. meinten, und auch das schwankende Urteil von Fritzsche und Langen hat damit einer sicheren Erkenntnis der Sachlage weichen 
müssen. Da gerade für unser Buch die Recension Lucians eine vom ursprünglichen LXX-Text aufserordentlich verschiedene Fassung bietet, lag die Versuchung zu jener Annahme nahe. Dafs dem aber nicht so sei, beweisen z. B. zwei Sätze, die wie sich weiterhin herausstellen wird, unbedingt der ursprünglichen Uebersetzung angehören. IV 9

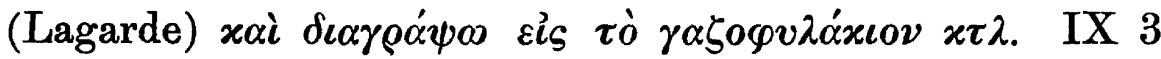

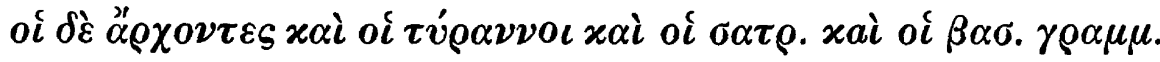

Es scheint, als wenn das Buch auch in dieser Recension ursprünglich vollständig gegeben war. So sind sonst Namen von Nebenpersonen fortgelassen z. B. die sieben Eunuchen, die sieben Fürsten, der Leibsclav Esthers, aber die Namen der zehn Söhne Hamans sind z. t. noch erhalten. Ferner hat diese Recension mehrere Zusätze, kleinere und gröfsere Umschreibungen, wie wir sie schon bei V. L. kennen gelernt haben. Durch ihre stark hebräische Färbung erinnern sie lebhaft an ein Targum, zumal Lucian im übrigen die hebräische Färbung zu verwischen bestrebt ist. So IV 6. 7. VII 5. 6. 13-17. VIII 2. 5. 6, ein kleiner Brief Mardechai's VIII 36-38. Es ist bereits oben ausgesprochen, dafs zwar die Möglichkeit einer Interpolation der V.L. nach Lucian nicht abzuweisen ist, dafs aber wahrscheinlicher in diesen Fällen eine andere Gestalt der LXX zu grunde liegt, die besonders durch die Obelen des Origenes gereinigt worden ist.

So wie der Text Lucians jetzt vor uns liegt, stellt er eine tief eingreifende Bearbeitung des Buches vor, welche freilich nicht consequent durchgeführt ist. Das zweite Kapitel des hebr. Buches ist stark gekürzt, v. 10-23 in wenige Zeilen zusammengedrängt; dgl. c. IV $1-10$; das ganze achte, das lange neunte Kapitel wird gleichfalls in wenigen Zeilen abgethan. Dafs überhaupt die selbständige Bearbeitung am Schlufs des Buches weniger sorgfältig ist und sich fast nur auf Kürzung beschränkt, beweist der engere Anschlufs an den Vulgärtext, von dem hier wenig 
abgewichen wird und u. a. die Namen 'A $A \tau \alpha \xi \xi \varepsilon \xi \xi o v$ VIII, 47 und $\Xi \varepsilon \rho \xi \eta v$ VIII, 52 während vorher consequent die

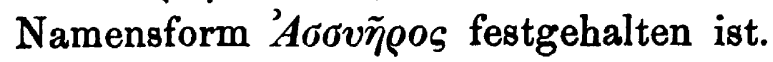

Allein wenn wir nun auch wissen, dafs wir hier die Lucianische Recension vor uns haben, so ist die Verlegenheit, in der wir uns befinden, durch die veränderte Fragestellung nicht geringer geworden. Denn um durch die verschiedenen Ablagerungen zu der Schicht echter LXX zu gelangen, müfste man zunächst alles dieser Fremde ausscheiden. Um dies aber zu erkennen, mülste man wissen, woher Lucian es entnommen. Hat er, wo er abweicht, unmittelbar aus dem Hebräischen übersetzt? - Es wird mehrfach versichert, dafs er es zu rate gezogen; oder entnahm er seine Ergänzungen und Verbesserungen aus Aquila, Symmachus, Theodotion oder noch andern? Und selbst wenn es uns gelänge, mit Hülfe von Mitteln, die wir jedoch vorläufig nicht besitzen, z. B. der Recension Hesych's, alles der ursprünglichen LXX nicht angehörige auszuscheiden, so müfsten wir doch noch gegen den Wortlaut dessen, was übrig bliebe, sehr mifstrauisch sein, da Lucians Recension sich in hervorragendem Mafse am sprachlichen Ausdruck bethätigt. Doch um wenigstens die erste Arbeit mit Erfolg zu leisten, könnten wir alle andern Mittel entbehren, wenn die hexaplarischen Ergänzungen, Randnoten u. s. w. wie sie in den Handschriften, besonders in $S^{m}$ und $93^{\text {b }}$ vorliegen, jedesmal mit dem Namen der Quelle versehen wären. Dann könnten wir aus denjenigen mit Namen versehenen Zusätzen, welche sich auch bei Lucian finden, ermitteln, welche Uebersetzer er benutzt hat. In der That findet sich eine Anzahl solcher Zusätze bei Lucian wieder, so I 1. 5. VI 18. VII 10. VIII 10. Es ist nun in hohem Grade wahrscheinlich, dafs vorzugsweise Aquila benutzt ist. Obgleich nämlich dieser nirgends namhaft gemacht ist, lälst er sich an einigen Stellen nachweisen. Im Midrasch תsther zu 16 חרגם עקילם אירינון קרפסינון heifst es וכרס 
d. i. Aquila übersetzt - $x \alpha \rho \pi \alpha ́ \sigma \iota \nu o v$; das erste Wort kann

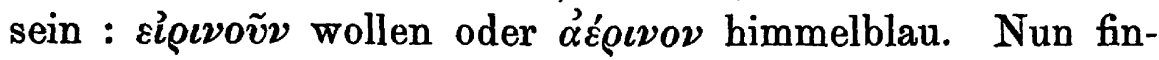
det sich zwar diese Variante zur Stelle nicht, wohl aber heifst es VIII 15 בלבוש תכלת ותור $\sigma \tau 0 \lambda \dot{\eta}$ hierzu $S^{\mathrm{m}} v \alpha x \iota v$ -

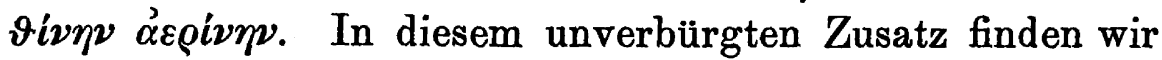
die verbürgte Uebersetzung Aquilas für חור wieder.

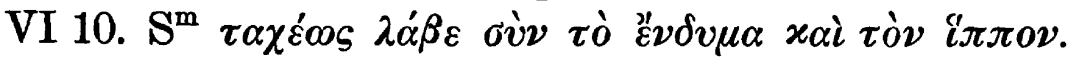
Wenn hier kein Fehler vorliegt, so kann die Uebersetzung

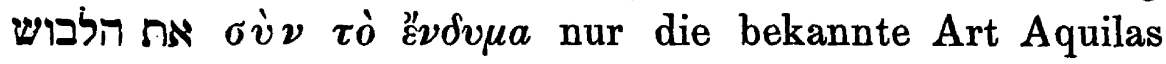
wiedergeben.

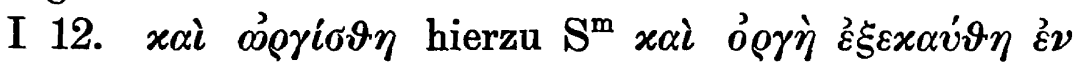

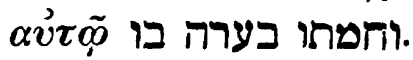

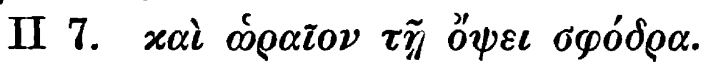

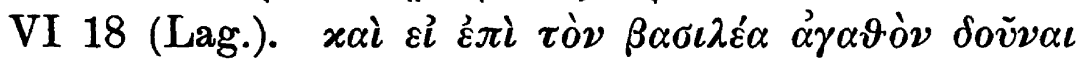

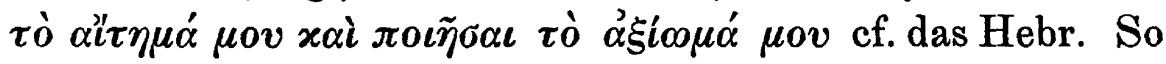
kann kaum ein anderer als Aquila übersetzt haben. Diese Uebersetzungen aber finden sich auch bei Lucian und die Uebereinstimmung mit $\mathrm{S}^{\mathrm{m}} 93^{\mathrm{b}}$ verbietet die Annahme einer selbständigen Uebertragung. Im übrigen ist die Recension Lucians so zerstörend für den LXX-Text gewesen, dafs sie von diesem nur noch Bruchstücke enthält. Dazu kommt endlich noch, dafs ihm ein sehr schlechter Text vorlag, der ihn oft irre führte und zu den sonderbarsten Mifsverständnissen verleitete. Am lehrreichsten sind hierfür, wie überhaupt für die ganze Art seiner Thätigkeit die Zusätze, bei denen die Hilfe sowohl eines andern griechischen als auch eines hebräischen Textes für ausgeschlossen gelten mufs. Dort kann man öfters beobachten, wie er sich mit einer falschen Lesart einzurichten sücht, cfr. (Lag.) I 8. xai oi $\pi \circ \tau \alpha \mu o \grave{v} v \psi \omega^{\prime}-$

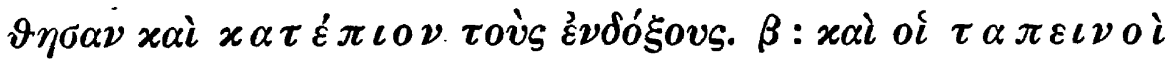

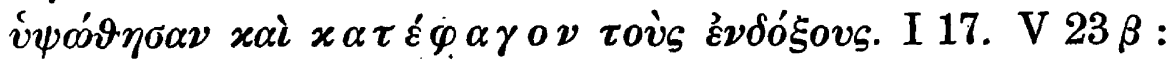

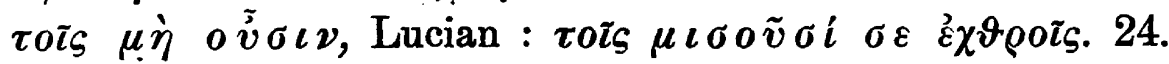

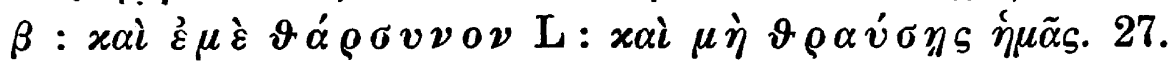

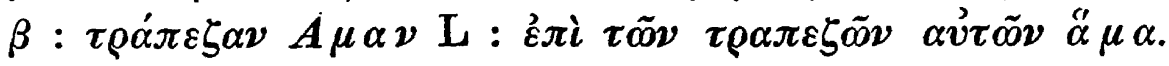
Aber auch im kanonischen Text sind solche Mifsverständ-

Zeitschrift f. d. alttest. Wiss. Jahrgang 10. 1890. 


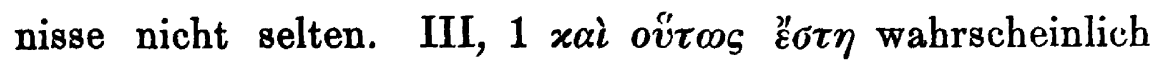

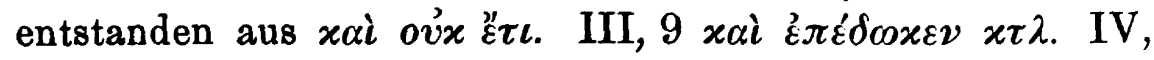

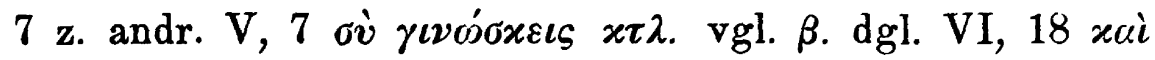

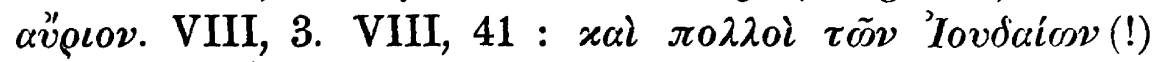

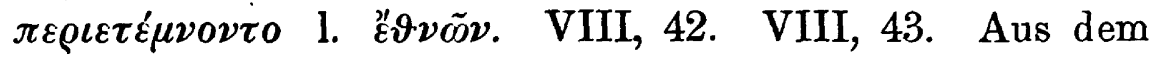
zweiten Sohne Hamans $\Delta \varepsilon \lambda \varphi \omega^{\prime} v$ wird $x \alpha \grave{i}$ ròv $a \dot{\delta} \varepsilon \lambda \varphi \dot{o} \nu$

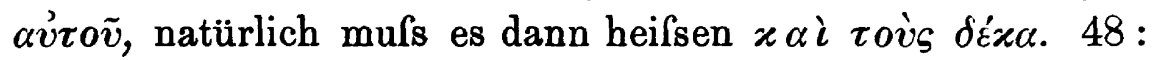

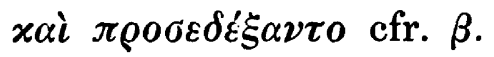

Erwägt man diese Fälle im Zusammenhang mit der sonstigen Art der Kedaction, so ist es nicht wahrscheinlich, dafs erst der Stammcodex von dhm an diesen quid pro quo schuld ist.

Jedenfalls zeigen diese Ausführungen, wie wenig bei unserm Buche Lucian für die Herstellung des echten Textes nützen kann. Doch bietet bei der Untersuchung die V.L. eine zwar mit Vorsicht zu gebrauchende, aber immer noch schätzbare Unterstützung.

\section{Josephus.}

Josephus erzählt in der Archäologie XI c. 6. die Geschichte E.'s als das letzte Ereignis der biblischen Geschichte, scheint daher mit diesem Buch den Kanon geschlóssen zu haben. Es erhellt auf das klarste, dafs $J$ die LXX nicht nur benutzt, sondern mit Ausschliefsung des Hebr. verwendet hat. Wir erkennen oft genug die eigenen Worte der LXX, aber da er natürlich nicht zitiert, ist er nur mit höchster Vorsicht oder als willkommene Bestätigung anderweitig bezeugter Textesthatsachen zu verwenden. Jedenfalls kann nicht die Rede davon sein, dafs er den Luciantext benutzt habe. Dies durfte auch nicht (wie von Langen geschah) behauptet werden, bevor dieser Text als derjenige Lucians erkannt war. Denn die beste Stütze für diese Annahme, die Langen gar nicht beachtet hat, ist, wie wir sehen werden, hinfällig; es sind die Namen

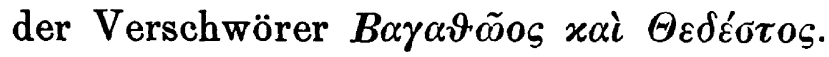


Mit diesen Hilfsmitteln nun : den Handschriften der LXX, der Vetus Latina (V), der Recension Lucians ( $\alpha$, den Vulgärtext bezeichnet $\beta$ ), Josephus $(J)$, dem hebräischen Grundtext (H) kann man immerhin einige Schäden des Textes zu heilen versuchen oder doch als solche bezeichnen. Die Zusätze, bei denen der Erfolg zum teil ein besserer sein wird, werden nach dieser Richtung an ihrem Orte behandelt werden.

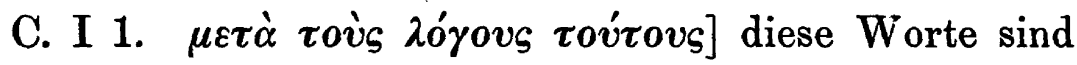
natürlich erst ein durch die Voranstellung von Add. I veranlafster redactioneller Zusatz vgl. V, 1.

$\dot{\alpha} \pi \grave{o} \tau \tilde{y}_{S}$ ' $\left.I \nu \delta \iota x \tilde{\eta} s\right]$ der Sinn verlangt und $\mathrm{V} \alpha \mathrm{JH}$ bezeugen

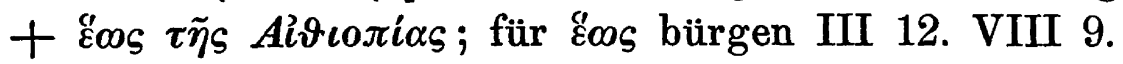

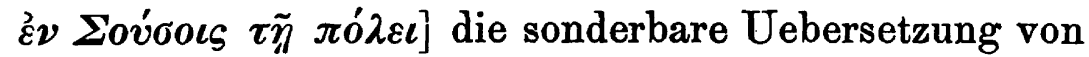
$\mathrm{V}$ zwar nicht hier, aber sonst oft : in Susa Thebari, kann

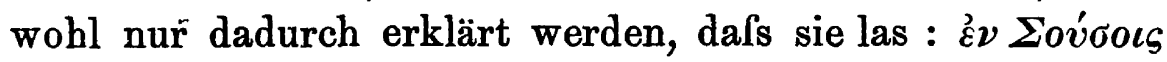

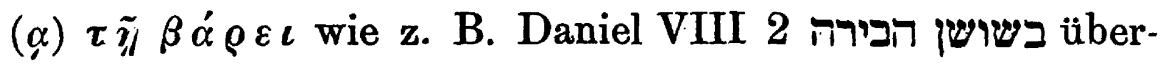
setzt wird, denn bisweilen schreibt auch sie: in Susa civitate. Doch im gr. Text findet sich nirgends mehr $\beta \dot{\alpha}$ ócs.

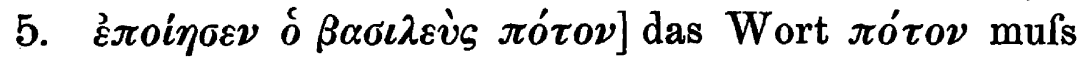
ursprünglich gefehlt oder an einer andern Stelle gestanden haben, denn sonst könnte die hexaplarische Note in $\mathbf{S}^{\mathrm{m}}$

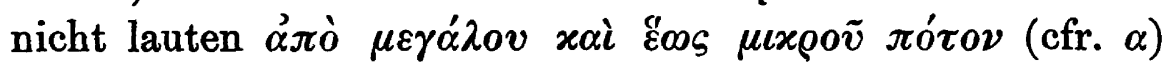
und dann erklärt sich auch auf diese Weise das Versehen von V (s. S. 252).


$\pi \varepsilon \pi \alpha \sigma \mu \varepsilon \dot{\nu} \alpha$ ist eine zweite Uebersetzung von ודר וסחרת

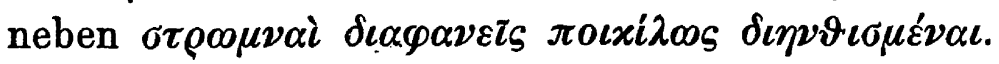

8. $\alpha v \dot{v} \tau o \tilde{v} x \alpha i] \mathrm{zu}$ streichen. $\mathrm{V} \alpha>$

9. öлоv ó $\left.\beta \alpha \sigma \iota \varepsilon \varepsilon v_{s}\right]$ lies entweder, wie der Sinn for-

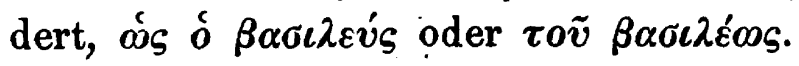

11. $\left.\left.\alpha \dot{v} \tau \dot{\eta}^{2}\right)\right]$ lies $\pi \tilde{\alpha} \sigma \iota \mathrm{ASV}$.

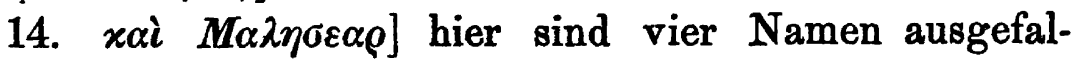
len VJ.

17. $\delta \iota \eta \eta \dot{\eta} \sigma \alpha \tau o]$ VH $\delta \iota \eta \eta \eta \vartheta \dot{\eta} \sigma \varepsilon \tau \alpha \iota$. 


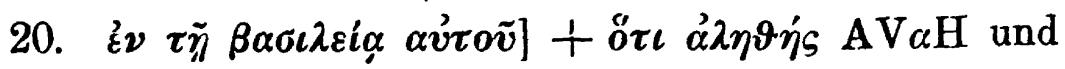
zwar um so wahrscheinlicher, als es eine falsche Uebersetzung von כי רבה היא ist.

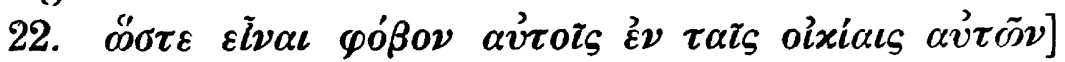
Dieser Vers ist jedenfalls eine verstümmelte Uebersetzung von להיות כל איש שרר בביתו ומרבר כלשון עמו. V. ut esset unusquisque princeps in domo sua et fuit timor magnus in omni muliere.

C. II 1. ovंx हैं $\tau$ ] ist zu streichen, denn es ist sowohl wider den Sinn als gegen AVS.

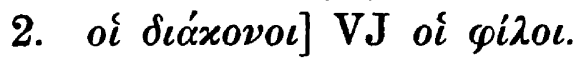

3. $\left.\pi \alpha \rho \alpha \delta \sigma \vartheta \dot{\eta}^{\prime} \tau \omega \sigma \alpha \nu\right]+\Gamma \omega \gamma \alpha i o \mathrm{~V} \alpha \mathrm{H}$.

6. $\quad \xi \xi I \varepsilon \rho o v \sigma \alpha \lambda \eta \mu]$ hier ist infolge von add. I, wohin

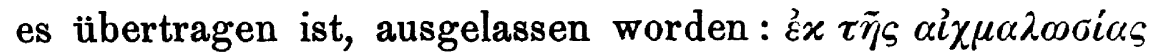

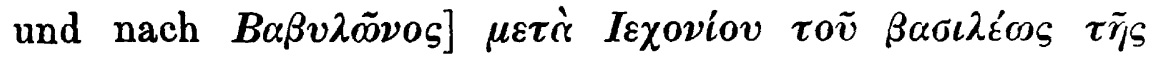
'lovdaias. V hat beides am Schlufs von c. III.

in v. 7 ist wahrscheinlich die Uebersetzung von לה אב ואם ausgefallen. V : quoniam erat orphana.

für $\gamma v v \alpha \tilde{z} x \alpha$ lies $\vartheta v \gamma \alpha \tau \varepsilon \dot{\varepsilon} \alpha \mathrm{VH}$.

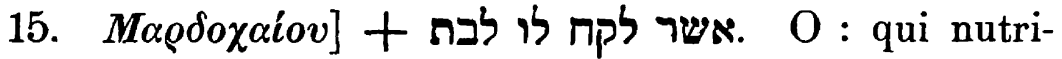
erat eam sibi in filiam.

17. jvvalxeiov] + וימליכה תחת ושתי V : et reginam eam fecit pro Vasthi.

über v. 21-23 s. weiter unten.

C. III 6, vor $x \alpha \grave{~} \varepsilon \beta o v \lambda \varepsilon v \dot{\sigma} \sigma \alpha \tau o$ ist die Uebersetzung des ersten Halbverses " ויבו - את עם מר ausgefallen :

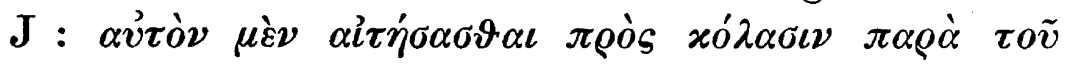

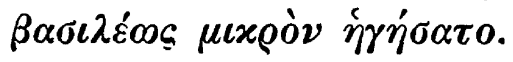

$\mathrm{V}$ : et quaerebat ei manus adicere ut perderet eum, ostenderunt autem ei genus Mardochaei.

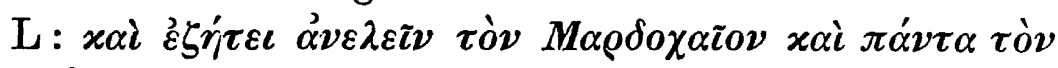
$\lambda \alpha \grave{\nu} \nu \alpha \dot{v} \tau o \tilde{v}$.

v. 7 fehlt בחרש הראשון הוא חדש ניסן. C : mense autem primo neomeniae (sic) $=\tau o \tilde{v} \mu \eta \nu o ́ s)$ qui est Nisan.

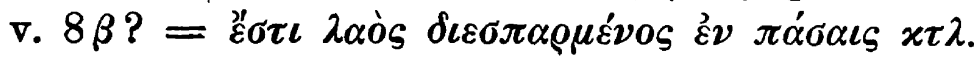


Symm.? Theod.? $=\dot{v} \pi \alpha \dot{\alpha} \propto \varepsilon \iota x \tau \lambda$.

d. h. $\alpha$ und $\beta$ mürsten die Verse tauschen, die Uebersetzung in $\alpha$ als die freiere und falsche scheint die ursprüngliche zu sein und zudem folgt ihr V. Vielleicht ist auch IV, 6 in $\alpha$ aus $\beta$ übernommen. Es scheint, als wenn bei diesem Verse die Columnen der Hexapla vertauscht worden sind. Aquila aber dürfte die andere Uebersetzung kaum angehören.

Im vierten und fünften Kapitel ist $\mathrm{V}$ besonders unzuverlässig wegen vielfacher Interpolationen, so dafs man nicht wagen kann, nach ihr zu verbessern. Ohne sie läfst aber auch $\alpha$ im Stich.

IV 13 ist vielleicht mit $\mathrm{AS}^{2}$ und $\mathrm{V} \sigma \omega 0 \vartheta \dot{\eta} \sigma o \mu \alpha \iota$ zu

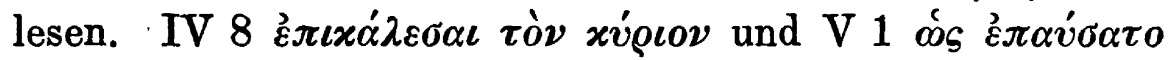


lafste Interpolationen.

VI 2 ist $\delta \_\delta a \sigma x \alpha \dot{\lambda} \lambda_{0}$ zu bezweifeln. V : Judaeorum autem deus gubernavit manum lectoris $\alpha: x \alpha \grave{\varepsilon} x \lambda \dot{\eta} \vartheta \eta$ $\sigma \alpha \nu$ of $\dot{\alpha} \nu \alpha \gamma \nu \tilde{\omega} \sigma \tau \alpha \iota$.

$J: \tau \dot{\nu} \nu \gamma \rho \alpha \mu \mu \alpha \tau \dot{\varepsilon} \alpha \ldots \alpha^{\prime} \nu \alpha \gamma \iota \nu \omega^{\sigma} \sigma \varepsilon \varepsilon \iota \nu \alpha \dot{v} \tau \tilde{\varphi}$ $\pi \rho \circ \varepsilon^{\prime} \tau \alpha \xi \varepsilon \nu$.

3. $\pi \varepsilon \rho i]$ hier sind die Namen der beiden Eunuchen ausgefallen. $\mathrm{V}:$ Hastageo et Thedesto.

v. 7. öv o $\left.\beta \alpha \sigma \iota \lambda \varepsilon \dot{v} \varsigma \vartheta \varepsilon^{\prime} \lambda \varepsilon \iota \delta o \xi \alpha \dot{\sigma} \sigma \alpha \iota\right]$ scheint Symm. oder

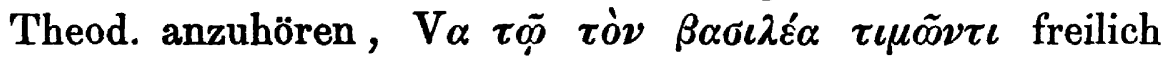
verkehrt, dgl. v. 9. 11.

v. 8. $\beta v \sigma \sigma i v \eta v]$ ist $\mathrm{zu}$ streichen $\mathrm{V} \alpha \mathrm{JH}$; vielleicht ist

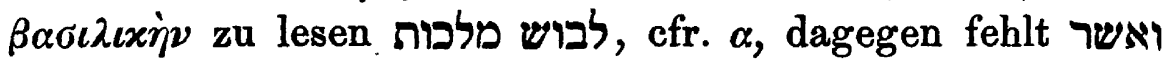
נתן כ : et corona aurea.

v. 12. $x \alpha \tau \dot{\alpha} x \varepsilon \varphi \alpha \lambda \tilde{\eta} s]$ lies nach $\mathrm{S}^{2}$ und $\mathrm{S}^{\mathrm{m}} x \alpha \tau \alpha x \varepsilon x \alpha-$

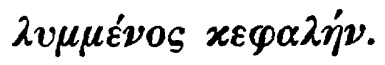

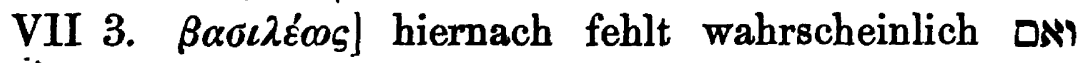

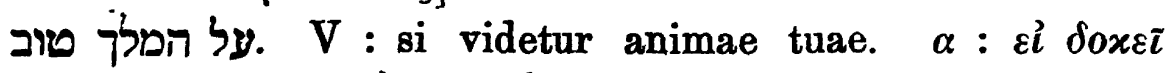


$\alpha \dot{v} \tau o \tilde{v}$. 


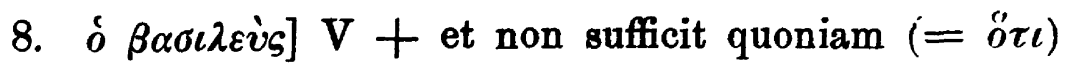
super me et regnum meum manus ausus fuit mittere. $\alpha$ :

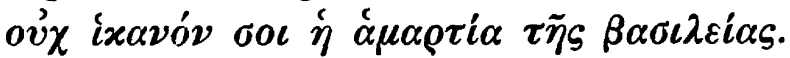

IX 10. $x \alpha i]+o v \delta \varepsilon \dot{\nu}$ vgl. IX 15.

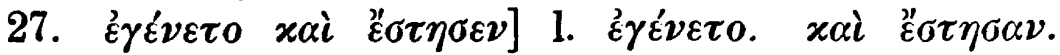
v. 28 bei de Lagarde eine Zeile höher zu rücken.

$\mathrm{X} 1$. ó $\left.\beta \alpha \sigma \iota \lambda \varepsilon v_{\zeta}\right]+\tau \varepsilon^{\prime} \lambda \eta$.

Man sieht, die Ausbeute ist gering und zum teil recht zweifelhaft, weil wir uns eben bei keinem Zeugen auf festem Boden bewegen und besonders bei einem Mehr in $\mathrm{V}$ nie wissen, ob es echt, ob hexaplarisch ist oder woher es sonst stammt. Aber erst nachdem diese Arbeit gethan ist, dürfen wir daran gehn, den griechischen Uebersetzer auf seine Eigenart, seine griechischen und hebräischen Kenntnisse und endlich auf seine Vorlage zu prüfen.

\section{* * * \\ II. \\ Der Charactor der Uebersetzung.}

Schon bei flüchtiger Vergleichung erkennt man, dafs der Uebersetzer nicht sowohl darauf ausging, das hebräische Wort als vielmehr den Gedanken des Satzes wiederzugeben. Daraus entspringt eine grofse Freiheit, die bisweilen zur Willkür wird. So wiederholen sich im Buche E. unaufhörlich die Worte המלך טחרושוש oder beide verbunden. Der Uebersetzer schreibt bald nur ó $\beta \alpha \sigma \iota \varepsilon^{2} s$,

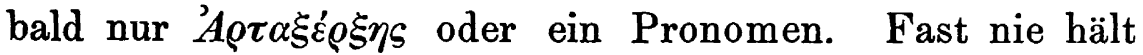
er an demselben griechischen Wort für ein hebräisches fest, sondern verwendet für die Wiedergabe desselben mehrere Synonyma oder umgeht es ganz durch Veränderung der Construction :

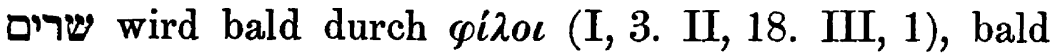
durch $\stackrel{2}{\alpha \chi \nu \nu \tau \varepsilon \varsigma ~(I, ~ 14 . ~ 16 . ~ 21) ~ u ̈ b e r s e t z t . ~}$

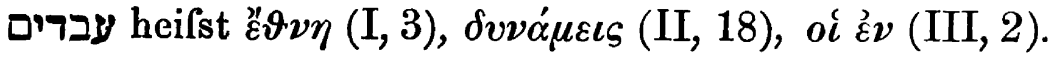




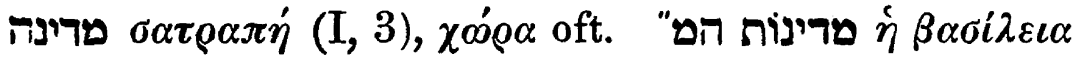

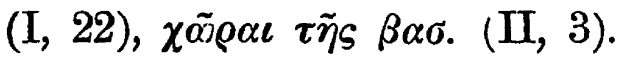

עמים

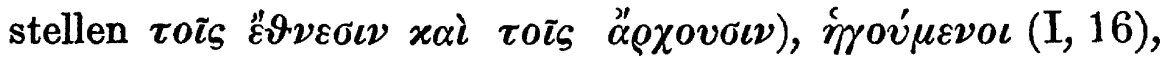

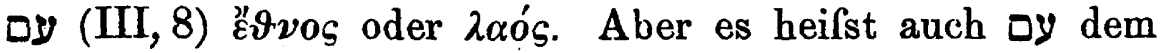
Zusammenhang gemäfs révos (II, 10), vgl. III, 13.




(I, 18).

בית heifst je nach dem Zusammenhang oíxos, $\tau \dot{\alpha} \ddot{\imath} \delta \iota \alpha$

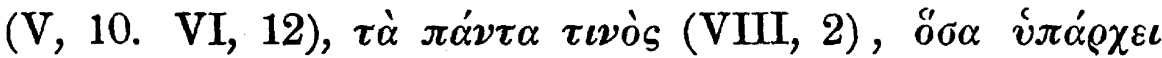
$\tau \iota v i$ (VIII, 1), $\tau \dot{\alpha} \dot{v} \pi \dot{\alpha} \varrho \chi o v \tau \alpha$ (VIII, 7).

Das Verbum בא wird natürlich oft mit $\bar{\varepsilon} \lambda \vartheta \varepsilon \tilde{\nu} \nu$ übersetzt,

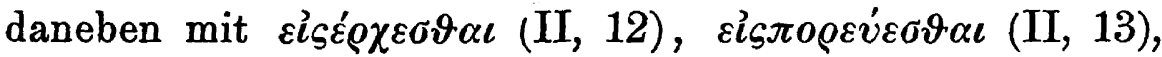
$\pi \alpha \varrho \alpha \gamma i v \varepsilon \sigma \vartheta \alpha \iota(\mathrm{V}, 5)$ oder die Construktion wird geändert. (I, 17) $\alpha \boldsymbol{\alpha} \nu \varepsilon \varepsilon \tau \pi \varepsilon v ; \pi \rho o s \varepsilon x \lambda \dot{\gamma} \vartheta \eta$ (VIII, 1). יבאה Jussiv

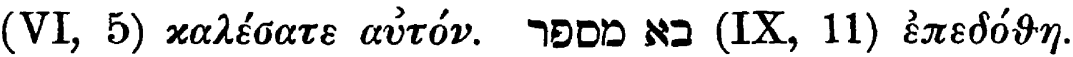

Diese Freiheit konnte der Uebersetzer besonders bei unserm Buche bethätigen, in dessen formelhafter Sprache gewisse Wendungen sich oft wiederholen und Häufungen nicht selten sind. In solchen Fällen pflegt der Uebersetzer den Ausdruck nicht in seinem ganzen Umfang wiederzugeben und von zwei oder mehreren parallelen Gliedern oft nur eines zu übersetzen :

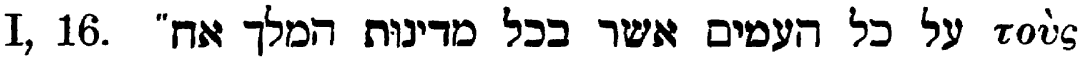

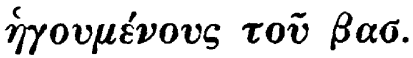

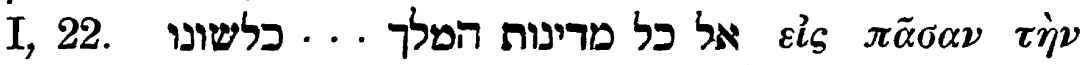

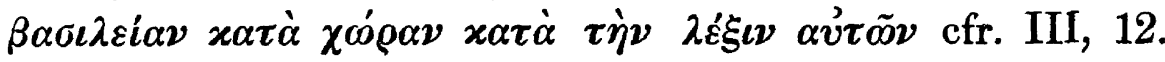
VIII, 9. 13.14.

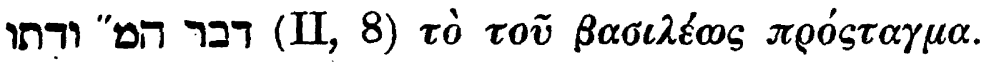

Die Formeln V, 3. VII, 2. V, 7. 8 sind bald genau, bald gekürzt wiedergegeben, den vier Gliedern der Formel



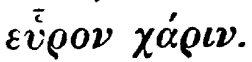

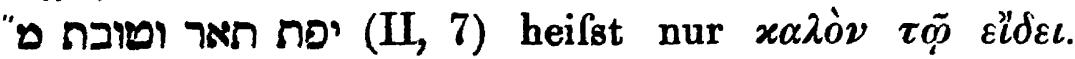




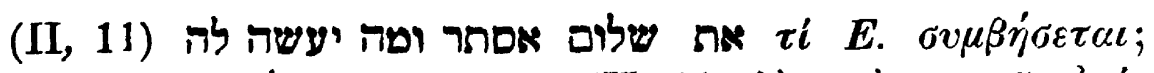

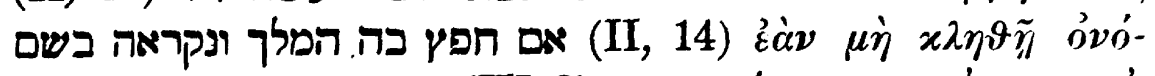


ולאבר (III, 13) à

So sind auch sonst häufig Worte fortgelassen, die בדבר 12

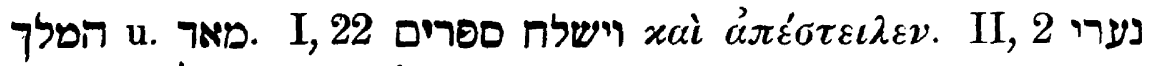

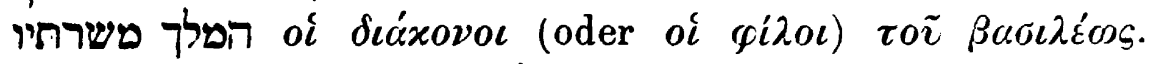
II, 12 כדת הנשים מלת מלכותו 16 u. dgl. m.

Mag hier auch manches durch die Schuld der Abschreiber ausgefallen sein, so ist diese Erscheinung doch so häufig und stimmt so wohl mit dem ganzen Charakter der Uebertragung, dafs man jene Annahme nur in wenigen Fällen gelten lassen und eher dem Uebersetzer die Schuld beimessen wird. So vermifst man I, 5 : למגרול וער קטן, II, ויתה משאת כיד המלך משרץ בתולות שנית II, III, 19 מנער וער וקן טף ונשים

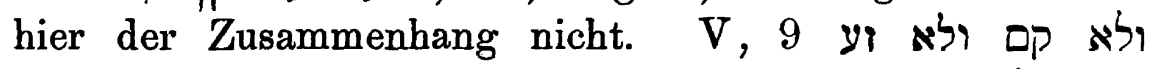

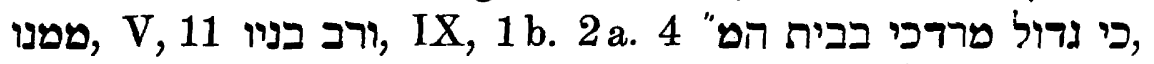

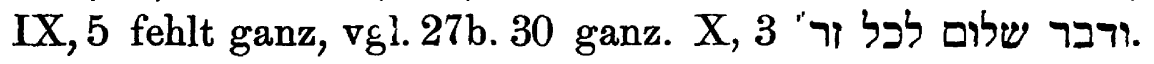

Ist der Uebersetzer für solche Nachlässigkeit zu tadeln, so ist andrerseits die bei aller Freiheit oft recht geschickte und gewandte Uebersetzung anzuerkennen.

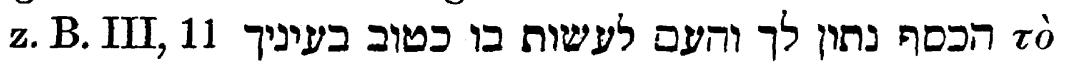

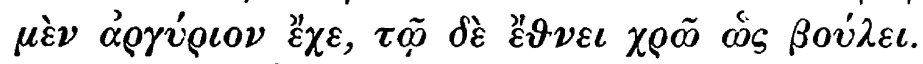

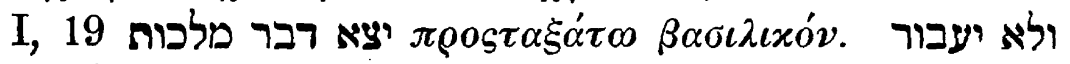

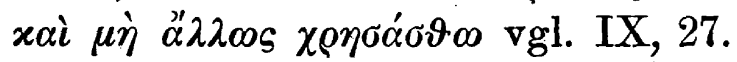





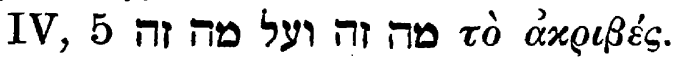

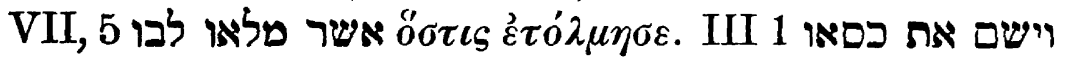



Bisweilen wird mit der Uebersetzung zugleich eine sinngemälse Exegese verbunden :

I, 20 : קטן אמגדול וער 


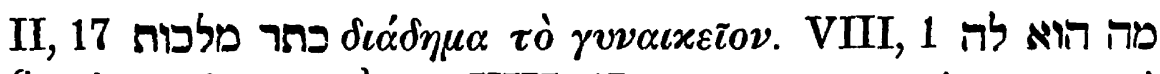

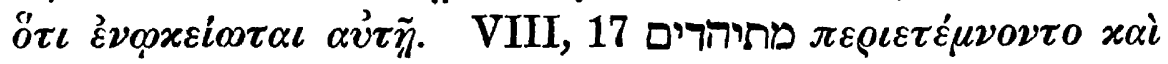

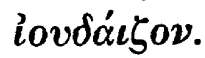

Andrerseits bleibt er sich in seiner Freiheit nicht immer gleich.

Von Substantiven, die im Sinn einer Präposition gebraucht werden, ist פנים stets durch einen Casus oder eine Präposition wiedergegeben, allein VI, 13 durch દ̇vóлıov,

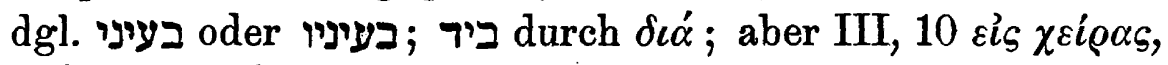
אל II, 8 vंлì $\chi \varepsilon \tilde{\varepsilon} \rho \alpha$.

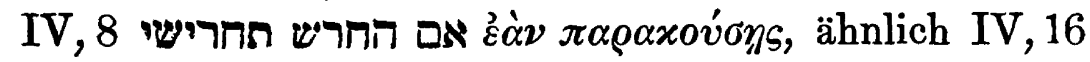



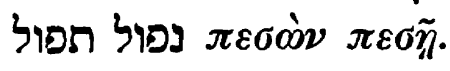

So günstig man also trotz mancher Mängel über die Gewandtheit der Uebersetzung urteilen darf, so ging doch die Kenntnis des Hebräischen nicht soweit, dafs nicht an den wenigen Stellen, welche an der im Allgemeinen leichten, fliefsenden Sprache des hebräischen Buches Schwierigkeiten machen konnten, gefehlt worden wäre. Dies trifft besonders bei Wörtern zu, die sich mehr dem neuhebräischen Sprachidiom nähern. So hat er VII, 4 mit dem Worte ichts anzufangen gewufst, so dafs der Sinn des Verses in sein gerades Gegenteil verkehrt wird. Aus diesem Grunde mag er ebendaselbst für לאבר gelesen oder übersetzt haben לעבד ( $2 i \zeta \delta o v \lambda \varepsilon i \alpha v)$. Desgleichen mifsversteht

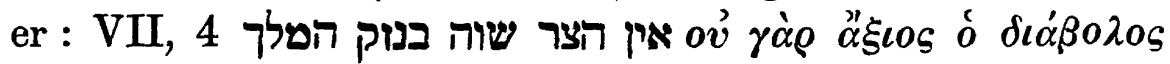

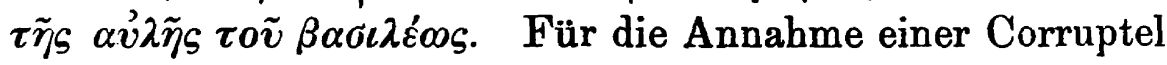
(óor $\tilde{\eta} \varsigma$ ), wie Ryssel im Commentar z. St. vermutet, bietet kein Zeuge eine Gewähr. Er umgeht eben, wie so häufig, die Schwierigkeit durch eine freie Uebersetzung. Auch II, הראיות לה (die ibr zukommenden) ist nicht ganz ge-

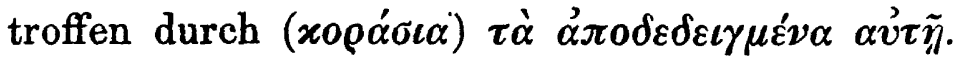

Scheint der Uebersetzer an diesen Stellen gerade späthebräische Wörter nicht gekannt zu haben, so mufs er an einer andern Stelle fälschlich eben ein solches gelesen 
haben. In I, 7, einem Verse, der mehrfach glossiert zu sein scheint, mufs der Uebersetzer irgendwo den Begriff ורר

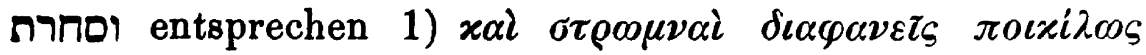


leicht für ורד das in der Bibel noch gar nicht vorkommende ורד (neuhebr.) das ja selbst nichts anders als das griechische ழóóov ist. Für סחר mufs die eine Ueber-

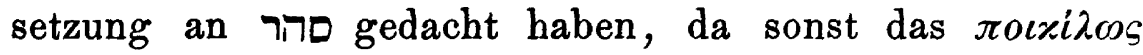
und $\delta \iota \alpha \varphi \alpha \nu \varepsilon \tilde{c}$ s unerklärlich wäre, die andere brachte es zusammen mit dem aramäischen סחור daher xúxגos.

Diese beiden Thatsachen nun, die Freiheit und Nachlässigkeit der Uebersetzung und die häufigen aus mangelnder Sprachkenntnis entspringenden Irrtümer machen die LXX Uebersetzung des Buches E. als kritischen Zeugen für den Originaltext mehr oder weniger wertlos. Denn da sie sich z. B. weder an den numerus noch modus des Originals bindet, so darf man noch keinesfalls annehmen,

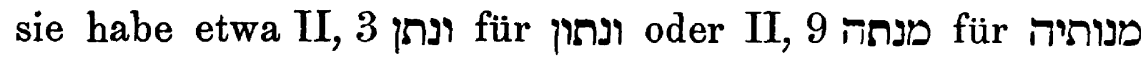
oder IV, ויניד 4 für וינידו und dgl. m. gelesen; selbst stärkere Abweichungen müssen eher auf die Freiheit der Uebersetzung z. B. IV, לרבים 3ibersetzt להם) oder mifsverständliche Auffassung z. B. II, 13 (עמה übersetzt עמ לם zurückgeführt werden. Im Ganzen leuchtet vielmehr aufs klarste überall der massoretische Text hindurch.

Nur bei den Eigennamen herrscht eine beispiellose Verwirrung ${ }^{1}$ ).

1) Ueber die Eigennamen in der LXX hat Könnecke im Programm des Stargarder Gymnasiums 1885 gehandelt, ohne, wie es scheint, die eindringenden Bemerkungen Frankel's in den Vorstudien zur LXX zu kennen. - Während des Druckes ist im zweiten Heft der theol. Quartalschrift 1890 ein Aufsatz von Scholtz : „die Namen im Buche Esther erschienen, welcher aus den griechischen Namensformen die weitgehendsten Schlüsse zieht. 
Von den etwa 60 Namen, die in unserm Buche vorkommen, sind einige verhältnifsmäfsig treu transscribiert.

Bei andern lassen sich selbst wesentliche Abweichungen noch erklären :

מדומן I, $10 A \mu \alpha \nu$ ist Verwechselung eines Schreibers C liest Maosma, P : Maosima; ebenso ist wahrscheinlich ein späterer Schreibfehler :

עמינבר II, 15 A A אביחיל 2 M. VI, 23 u. ö. denn C : Chiel, $\mathrm{O}$ : Abihel.

טבת II, $16 A \delta \alpha \varrho$ ist bereits durch Josephus u. V bezeugt und vielleicht ebenso chronologische Berechnung wie סיון VIII, 9 Nıoav.

Eine Anzahl Namen lautet in griechische Endung aus und zwar nicht blos solche, welche die Gräcisierung durch auslautenden Vocal oder Vocalbuchstaben begünstigen :

זיר II, 5 'Iai

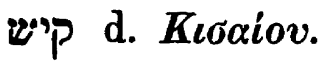

Namen, die bereits in griechischer Form vorhanden sind :


Einige Namen fehlen ganz oder sind ausgefallen הדסה ברס II, 7, שעשנו II, 14. Für בגתן ותרש II, 21. VI, 2 und drei der sieben Fürsten I, 7 bürgen überdies Zeugen.

Alle andern aber sind in solcher Verwirrung, dafs nur bei wenigen noch das Hebr. hindurchschimmert.

Mögen auch die Hände von Abschreibern vieles verstümmelt haben, so zeigen doch die bei Josephus vor-

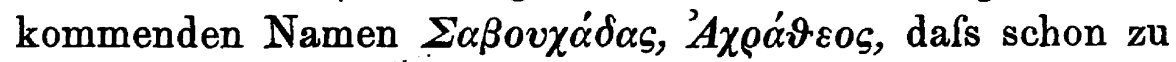
seiner Zeit gewisse Namensformen, die mit dem Hebr. durchaus nicht in Einklang $z u$ bringen sind, vorhanden waren. Solche Abwęichungen können aber nicht blos auf die entstellende Feder der Kopisten zurückgeführt werden. Das Buch mufs, und dies wird noch eingehender begründet werden, durch Bearbeitungen hindurchgegangen oder von solchen beeinflufst sein, die den hebräischen Text nicht 
mehr kannten oder sich dermalsen von ihm lossagten, dafs sie mit gröfster Freiheit Namen unterstellten, für die die Urschrift nicht mehr den geringsten Anhalt bot. Aehnlich mag es sich mit 'A

Je weniger der Uebersetzer, wie wir sehen, sich an das hebräische Wort- und Satzgefüge hält und dem eigenen griechischen Sprachgefühl folgend eher die Genauigkeit als den griechisch sprachgemäfsen Ausdruck opfert, um so sicherer können wir die Regeln seiner Sprache feststellen, ohne Besonderheiten aus der Gebundenheit des Uebersetzers erklären zu müssen. In der That finden sich nur wenige Hebraismen; sie sind aber z. t. mehr ein Zeichen seiner Nachlässigkeit als seines Unvermögens, da sie an

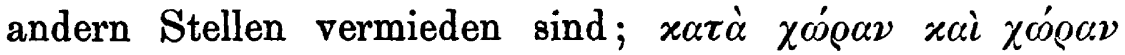

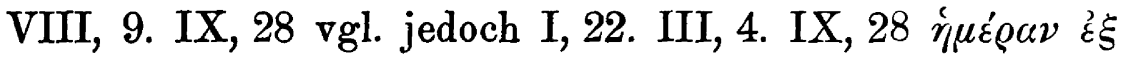

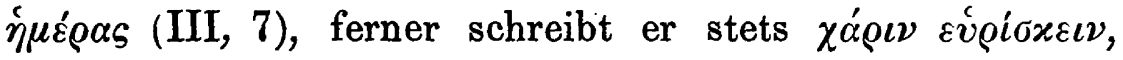
nicht nur V, 8 für מצא חן, sondern auch II, 9. 15. 17.

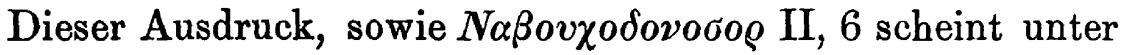
dem Einflufs von bereits vorhandenen Uebersetzungen anderer Büchcr zu stehn. $\pi \varepsilon \sigma \dot{\nu} \nu \pi \varepsilon \sigma \tilde{\eta}$ VI, 13, vgl. dagegen

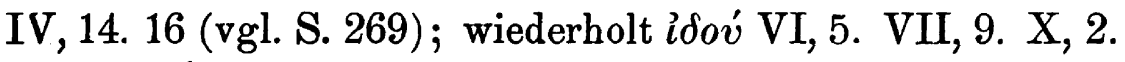

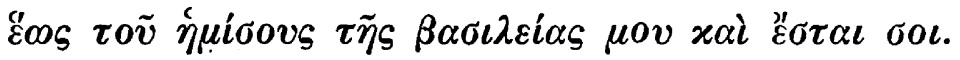

Von diesen wenigen Fällen abgesehen, ist der Ausdruck zwar nicht elegant, aber durchweg den allgemeinen Regeln der xoıv' folgend, wenn auch manche Erscheinungen bereits ein sinkendes Sprachgefühl verraten.

In der Setzung des Artikels, Stellung von Adjectiven oder Genetiven, Construction von $\pi \tilde{\alpha} \varsigma$ kommen keine Besonderheiten vor.

Im Gebrauch des Pronomen ist eine grofse Armut zu

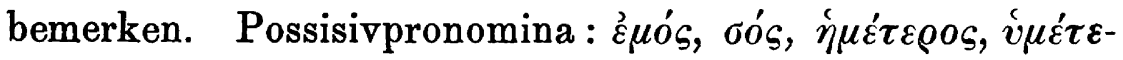

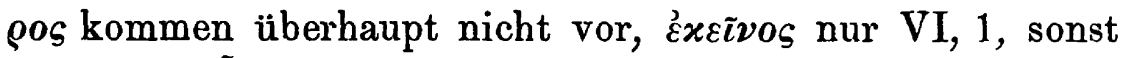
wird nur oṽ $\tau o s$ und avंós verwendet. Auffallend ist das Schwanken zwischen $\alpha \hat{v} \tau o \tilde{v}$ und $\mathfrak{\varepsilon} \alpha v \tau o \tilde{v}$, letzteres kommt zwar in reflexivem Sinne vor I, 20. II, 7. IV, 1. VII, 7 selbst 


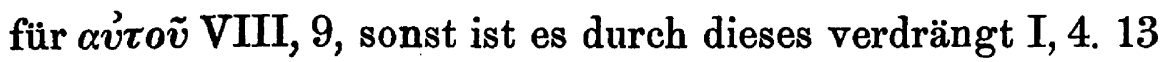
u. sehr oft, doch mögen darin die Codices nicht zuverlässig

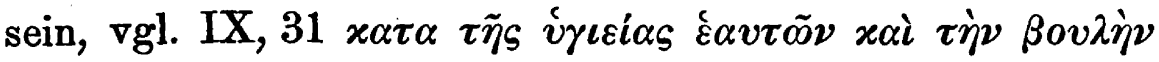

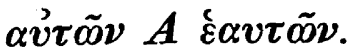

Was die Verwendung von Verbalformen angeht, so ist die Erzählung meist durch den Aorist gegeben, nur bisweilen tritt bei Bezeichnung wiederholter Handlungen oder von Zuständen das Imperfect ein III, 2. 4. VIII, 17. IX, 3. Mehrere Male ist das Perfect gesetzt V, 12. VIII, 1. VII, 9 und einmal das Plusquamperf. VII, 8 beides durch den Zusammenhang gerechtfertigt. Ein ausgiebiger Gebrauch wird von dem Infinitiv gemacht; Infinitivsätze in jeder Bedeutung sind so häufig, dafs sie nicht blos aus Bequemlichkeit, sondern aus mangelndem Gefühl, das Satzverhältnis bestimmter ausdrücken zu sollen, erklärt werden müssen. I, 8. 11



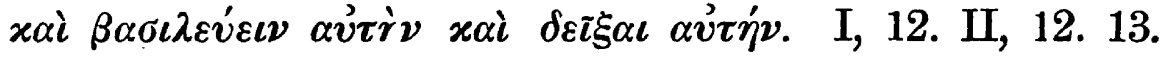
15. IV, 5. 8. 11. V, 11. VI, 1.4 u. s. f. Häufig sind auch substantivirte Infinitive mit einer Präposition, selbst dort, wo das hebr. nicht dazu nötigte : I, 4. II, 7. 15. IV, 8. V, 9. VI, 2.3, jedoch sind ebenso häufig Participia und Genetivi absoluti I, 3.10.18. II, 11. 15. III, 8. IV, 2. 4. 15. 17. V, 2. 9. 10. VI, 1. 4. VII, 7. 8 9. VIII, 3. 8. IX, 11.22. Dadurch gelingt es, das einfache hebräische Satzgefüge zu heben :



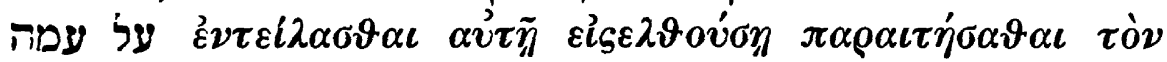

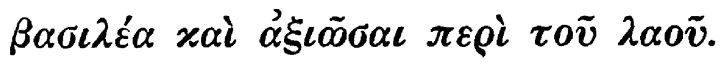

Ebenso auffallend wie der häufige Gebrauch abhängiger Infinitivsätze ist das Fehlen des Optativs, selbst an Stellen, wo man ihn bestimmt erwarten sollte II, 4. VIII, 6. VIII, 11 . Entweder steht in diesen Fällen das Fut. oder Praes. Ind.

Im Gebrauche von Präpositionen kommen keine Besonderheiten vor.

Verba, welche mit einer Präposition zusammengesetzt sind, haben ebenso oft den Casus ihrer Präposition als sie 
diesolbo wiedorholon (I, 14. IV, 4. 5. V, 2.11. VI, 2. 8. VII, 1. 8. VIII, 3. 4. 7. IX, 3. IX, 25).

Von Partikeln wird nicht allein xal gesetzt, sondern sohr hllufig dé (otwa $70 \mathrm{mal}$ ), $\mu t \nu$, ơv $, \tau t-x \alpha \ell, \mu t v-\delta \varepsilon$ (III, 11) - $\gamma \dot{\alpha} \rho$, das der Ucbersetzer Ezechicls in 48 Capitoln nur droimal schroibt, sotzt der unsrige in nur 10 Capiteln immerhin 14 mal.

Dor Gobrauch von Conjunctionen beschrinkt sich auf

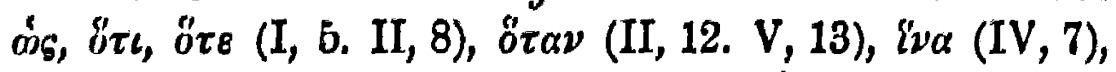
"̋ros $(\mathrm{V}, 4)$ und die Bedingungsconj: $\ell \dot{\alpha} v$ (im Relativeatz I, 20. II, 4. IV, 14) und $\varepsilon$; letzteres geht einigemal in dio Bedoutung : da, nachdom, uber VI, 13. VIII, 7.

Diose Anfuhrungen werden genugen, den sprachlichen Charakter der Uobersetzung zu kennzeichnen. Sie beweison, daf's der Uebersetzer dor griechischen Sprache in nicht geringem Grade mächtig gewesen sein mufs. Soin Ausdruck, von IIebraismen fast gänzlich frei, ist bisweilen schwerfullig, orgiebt aber im ganzen eine lesbare Prosa, so dafs die Uoborsetzung auch ohne das Original sohr wohl zu verstehen näro.

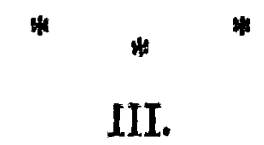

Zeit und Ort dor Abfassung.

Am Ende des Buches E. findet sich in $\beta$ und $h, j e-$ doch nicht in V, folgendo Nachschrift :



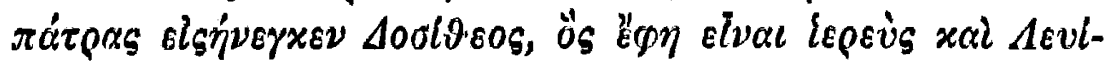

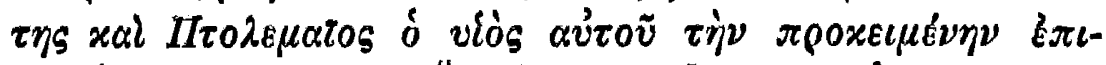



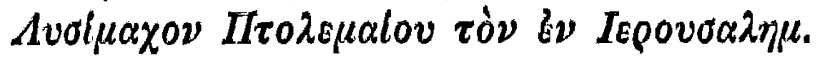

Nach dieser Notiz wurdo also behauptet, dafs dio vorliegende Uebersetzung des Buches E. (denn ob mit z $\pi$ $\sigma \tau 0 \lambda \dot{\eta} \tau \tilde{\omega} \nu$ $\varphi \rho$. nur dieses gemeint sei, mag vorerst dahingestellt bleibon) in Jerusalom angefertigt soi und zwar von 
Lysimachus, dem Sohne des Ptolemaeus. Diese Uebersetzung hätten Dositheos, nach seiner eigenen Angabe Priester und (!) Levit, und sein Sohn Ptolemaeus mitgebracht (d. h. doch wohl nach Aegypten) und zwar im vierten Jahre der Regierung (des ägyptischen Königs) Ptolemaeus und der Kleopatra.

Also anscheinend in aller Kürze eine sehr eingehende Nachricht, die durch die Angabe der Zeit, die Häufung von persönlichen Bestimmungen, den Eindruck einer glaubhaften geschichtlichen Bemerkung macht; um so wichtiger und wertvoller, als wir über kein Buch der LXX, ausgenommen das Buch des Siraciden, derartige Angaben besitzen. Sie verdient daher eine genaue Prüfung.

Zunächst mufs mit Pt. und Kl. unzweifelhaft ein Ehepaar gemeint sein, denn ein anderes Verhältnis, etwa von Mutter und Sohn, hätte als solches gekennzeichnet werden müssen, wenigstens durch Voranstellung von Kl. Ein Ehepaar haben denn auch sämtliche Gelehrte, die sich mit der Stelle beschäftigt haben, angenommen. Dadurch beschränkt sich die Anzahl der in Betracht kommenden Ptolemäer bei der an Ausschlielslichkeit grenzenden Verwendung dieses Mannsnamens im Königsgeschlecht der Lagiden von vornherein auf vier. Denn nur vier von ihnen, die auf dem Throne safsen, waren mit einer Kleopatra vermählt : Ptolemaeus V-VIII : Epiphanes, Philometor, Physcon, Lathuros. Unter diesen haben sich die meisten Gelehrten für Philometor entschieden, weil unter dessen judenfreundlicher Regierung, während:welcher der Bau des Tempels zu Leontopolis durch Onias stattfand ${ }^{1}$ ) und somit das religiöse Bedürfnis der ägyptischen Juden seine Befriedigung fand, es nahe lag, das Buch E., das ein neues Nationalfest einsetzte, -zu übertragen und bekannt zu machen. Einige

1) Jos. Antiqq. 13, 3. 
haben selbst unsern Dositheos bestimmen zu können geglaubt als den Jos. c. Apion. II, 5 genannten Oberbefehlshaber des ägyptischen Heeres $^{1}$ ). Diese Identifizierung ist aber eine durch nichts gerechtfertigte und auch von Fritzsche $^{2}$ ) gemifsbilligte Vermutung. Denn der Name D. ist sehr häufig. D. heifst ein maccabäischer Anführer 2 Macc. 12, 19 und in demselben Kapitel v. $39 \mathrm{f}$. wird das Wagstück eines andern D. erzählt, der mitten in der Schlacht den feindlichen Feldherrn Gorgias, den Statthalter von Idumaea, ergriff und gefangen nehmen wollte; und im dritten Maccabäerbuch I, 3 wird ein D., Sohn des Drimylos genannt, ein geborener, aber abtrünniger Jude; ein Beweis, wie häufig dieser Name grade unter Juden war. Jene Vermutung ist aber an sich in hohem Grade unwahrscheinlich; zwar ist es nicht undenkbar, dafs der spätere Oberbefehlshaber des ägyptischen Heeres sich mit der Einführung einer griechischen Uebersetzung des Buches Esther befal'st habe, dann könnte seine Bezeichnung als Priester nur ein Gentilicium sein sollen; aber mit dem hier genannten ist offenbar ein Palästinenser gemeint, den man in Aegypten gar nicht kannte, daher der Ausdruck

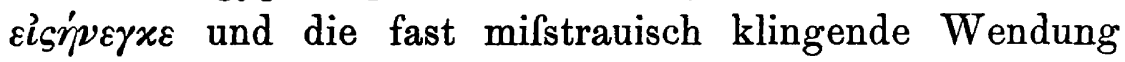


ches konnte aber dem jedenfalls von ägyptischem Standpunkt schreibenden Verfasser der Notiz so unbekannt nicht sein. Schliefslich übersieht man, dafs D. mit seinem Sohn Ptolemaeus das Buch mitgebracht haben soll. Auch dieser muls also erwachsen und mit ähnlichem Ansehen auftretend gedacht werden, wenn seine Erwähnung nicht gänzlich überflüssig erscheinen soll.



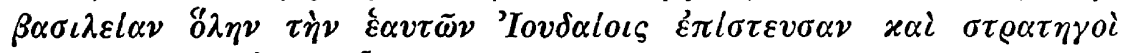

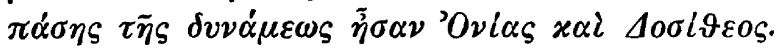

2) Exegetisches Handbuch zu den Apocryphen des Alten Testam. I, 73. 
Andere haben den Namen Kleopatra fallen lassen und sich nur an Ptol. haltend an Philadelphus gedacht dieser hatte zwei Frauen nach einander, die beide Arsinoe hiefsen - oder an Philopator - dessen Gemahlin gleichfalls Arsinoe hiefs - und dann glaubten sie in D. den obenerwähnten des dritten Maccabäerbuches wiederzufinden, aber gleichfalls ohne ausreichende Gründe.

Wenn man aber so wenig Gewicht auf den Namen Kl. legt, ist es fast zu verwundern, dafs, wie es scheint, noch niemand an den Dos. gedacht hat, der im Aristeasbrief (ed : Schmidt in Merx Archiv f. altt. Forsch. I. 23) unter den 72 Uebersetzern und zwar als der sechste aus dem elften Stamm genannt wird. Aber wie handgreiflich ersonnen und mit wie armseliger Erfindungsgabe zusammengelesen sind diese Namen $!^{1}$ )

Bei allen Bestimmungen nun ist jedoch in der Regel ein Moment aufser Acht gelassen worden ${ }^{2}$ ), das von

1) Unter den 72 Namen kommen mehrere 2 und 3 mal, einer: 'I $\dot{\text { - }}$ $\sigma \eta \pi o \varsigma$ selbst 4 mal vor, ef. Lumbroso : recherches sur l'économie politique de l'Egypte sous les Lagides Turin 1870 p. 353. Ein Princip in der Zusammenstellung der Namen ist nicht erkennbar, ebenso wenig wie bei den 72 Fragen, deren der König jedem eine vorlegt. Dagegen ist bei den Antworten der Grundsatz festgehalten worden, jede mit einem Hinweis auf Gottes Macht, Gebot oder Beispiel zu schliefsen, um dem König, das ist offenbar der Hauptzweck, zu zeigen, wie alle Weisheit und Erfahrung der Weisesten und Erfahrensten aus dem jüdischen Volke von Gott stamme, und ihn selbst zar Verehrung dieses Gottes zu führen. Darauf ist auch zweimal deutlich hingewiesen 48, 8

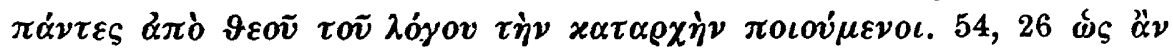

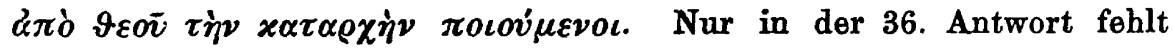
jeder Hinweis auf Gott. Daher ist gewifs $56,5 \mathrm{zu}$ lesen $2 \lambda \lambda \dot{\alpha} \vartheta \varepsilon \dot{\partial} \nu$


die Frage : Giebt es ein Mittel gegen unruhigen Schlaf?) mufs der Hinweis auf die $\varepsilon \dot{b} \delta \varepsilon \varepsilon \varepsilon \iota \alpha$ genügen, wenn nicht auch hier in dem verdorbenen Text irgendwo $\vartheta \varepsilon o ́ s$ steckt.

2) Nicht jedoch von Herzfeld. Er schreibt gegen Frankel und Eichhorn, welche Philometor annehmen (Gesch. II, 556). Ich will nur

Zeitschrift f. d. alttest. Wiss. Jahrgang 10. 1890. 
den vier Ptolemäern ohne weiteres die drei ersten ausscheidet.

Man darf nämlich nicht fragen : Welche Ptolemäer waren mit einer Kleopatra vermäblt, sondern welche waren es im vierten Jahre ihrer Regierung? Wenn man auch nicht darauf dringen will, dafs das gedachte Jahr das vierte beider sein müsse, so mufs man doch daran festhalten, dafs dieser Ptolemäer im vierten Jahre seiner Regierung mit einer Kl. verheiratet gewesen sein muls.

Gehen wir nun an der Hand dieser Bedingung die vier Ptolemäer durch.

Da ist denn an Ptol. V Epiphanes gar nicht zu denken, denn als sein Vater Philopator 204 starb, war er im fünften Lebensjahr ${ }^{2}$ ); er kann also im vierten Jahre seiner Regierung 201 nicht verheiratet gewesen sein, vielmehr wurde er mit Antiochus d. Grofsen Tochter Kleopatra im Jahre 193 vermählt.

Ganz in derselben Lage befinden wir uns bei Ptol. VI Philometor; denn als durch den Tod seines Vaters 181 der Thron für ihn frei wurde, war er sechs Jahre alt. Er heiratete wahrscheinlich ${ }^{3}$ ) erst 165 . Dafs aber mit Kl. die Mutter und Vormünderin eines der beiden gemeint sei, ist nach der Fassung der Worte unmöglich. Ptolemaeus VII Euergetes II mit dem Spottnamen Physcon (Wanst), regierte mit seinem Bruder Philometor, nachdem er sich mit ihm ausgesöhnt hatte, 170-164 gemeinschaftlich und

vorweg bemerken, dafs der sorgfältig Eingehende keine weiteren Ptolemäer, die im vierten Jahre ihrer Herrschaft über Aegypten diese mit einer Kl. geteilt hätten, finden wird als Philometor, Physcon und einen der beiden nach Physcon's Tode abwechselnd regierenden Söhne desselben. Auch Grätz nimmt in der neuesten Auflage des 3. Bd. der Gesch. seine frühere Ansicht über Philometor und Dositheos zurück.

2) Justin 30, 2, Hieronymus ad Danielem XI 13. Dazu Letronne recueil des inscriptions I $264 \mathrm{f}$.

s) Letronne p. 22. 
nach dessen Tode 146-117 allein. Er heiratete zwar, durch die politische Lage gezwungen, alsbald seine Schwester, die Witwe seines Bruders, Kleopatra, verstiefs sie jedoch bald, um ibre Tochter, seine Nichte gleichen Namens, zu heiraten. $E r$ könnte also gemeint sein, und das vierte Jahr seiner und Kl.'s, sei es der ersten oder zweiten, Regierung das Jahr 142/41 sein, wenn nicht aus Porphyrius in Eusebius Chronik feststände, dafs die Regierungsjahre Physcon's nicht von der zweiten, sondern von der ersten Thronbesteigung 170 gezählt wurden Im Jahre 167 aber war er, 182 geboren, gleichfalls noch unmündig und unvermählt.

Es bleibt also nur noch Ptol. VIII Soter II Lathuros 117-81. Er. ist denn auch der einzige, auf welchen das Datum gehen könnte. Denn er heiratete, 144 geboren, seine Schwester Kleopatra im Jahre 127 und obgleich er gerade im vierten Jahre seiner Regierung 114 zum zweiten Male heiratete und diese Gemahlin Selene hiefs, könnte er in diesem Jahre noch mit seiner ersten Frau zusammengenannt sein.

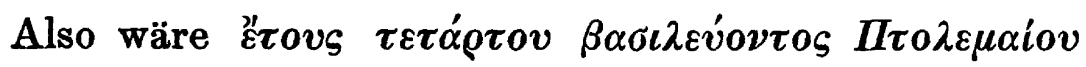

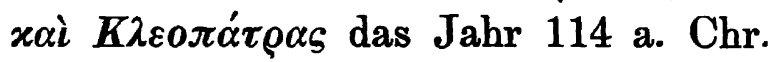

Allein diese schwankende, unbestimmte Art der Zeitbestimmung aufserhalb jedes geschichtlichen Zusammenhangs erweckt der Notiz wenig Vertrauen, da es dem Verfasser durch ein einziges Wort möglich war, die genaueste Bestimmung zu geben. Ja die Vieldeutigkeit der Namen mufste ihn hierzu, wenn er überhaupt deutlich sein wollte, herausfordern. Grade das Gegenteil scheint jedoch seine Absicht gewesen zu sein.

Die anderen in der Ueberschrift genannten Personen geben uns noch weniger Anhalt, da sie durchaus unbekannt sind.

Es soll endlich, will uns die Nachschrift glauben machen, die Uebersetzung von einem Jerusalemer ange- 
fertigt und aus seiner Heimat irgendwohin, doch wohl nach Aegypten, gebracht worden sein. Das wäre, wenn wahr, eine lehrreiche Thatsache. Also ginge die Abhängigkeit der ägyptischen Diaspora vom Stammlande so weit, dafs sie von dort nicht nur die Grundschrift ihrer heiligen Bücher mitgenommen hätte, sondern auch die Uebersetzung eines einzelnen Buches hätte sie von dorther erhalten. Man weifs nicht, ob man hier mehr in Betracht ziehen soll die Unkenntnis des Hebräischen in Aegypten oder die Kenntnis des Griechischen in Palästina. Das letztere wäre jedenfalls das bemerkenswertere. Wissen wir doch, wie gering und dürftig die Kenntnis der griechischen Sprache in Palästina gewesen ist von Eupolemos, dem Zeitgenossen der Maccabäer bis auf Josephus und die neutestamentlichen Schriftsteller ${ }^{1}$ ). Josephus gerade beweist durch sein eigenes Geständnis, wie ungemein schwer es für einen geborenen Palästinenser wurde, sich zur Beherrschung der griechischen Sprache emporzuarbeiten. Wir haben aber gesehen, dafs unsere Uebersetzung unleugbar Kenntnis und Beherrschung der Sprache verrät.

Diese Angabe zu bestätigen oder zu widerlegen ist der einzige Weg, die Uebersetzung selbst nach solchen Bestandteilen zu durchforschen, welche ein bestimmtes Vaterland bekunden. Eine solche Prüfung führt uns mit Sicherheit zu dem Ergebnis, dafs sie nirgends anders als in Aegypten gemacht sein kann. Denn sie spiegelt mit voller Deutlichkeit ägyptische Verhältnisse, ägyptische Einrichtungen, ägyptisch-griechisches Sprachgefühl wieder. Dieser Nachweis kann an einer Anzahl Wörter und Begriffe geführt werden, an denen diese Merkmale fast ausnahmslos mit Sicherheit zu erkennen sind.

Im zweiten Verse des ersten Kapitels werden die Worte : כשבת הטלך א" על כםא מלכותו :Als der König A.

') vgl. Freudenthal : hellenistische Studien II, 126. 
auf seinem königlichen Throne sals" folgendermafsen wie-

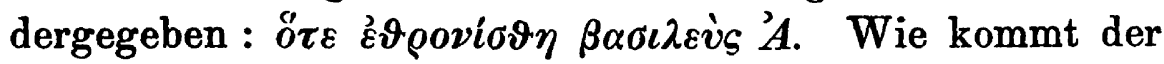

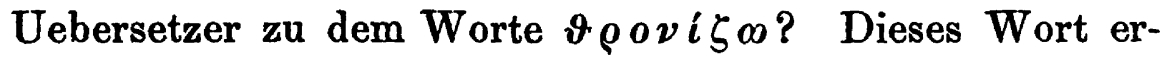
scheint erst in der späten byzantinischen Gräzität und auch hier nur vereinzelt und in anderer Bedeutung. Wohl

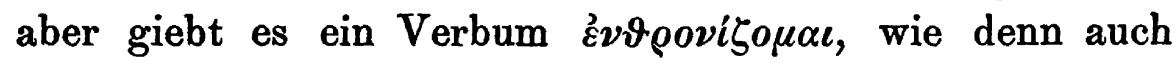

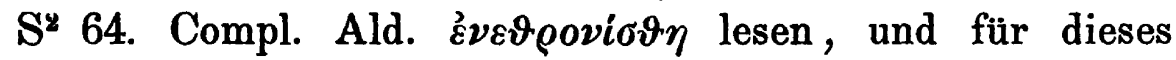
Compositum mufs das Simplex gesetzt oder verschrieben sein. Jenes Verbum aber, sowie das davon abgeleitete Substantivum $\dot{\varepsilon} v \vartheta \varrho o \nu \iota \sigma \mu o ́ s$ ist ein besonderer ägyptischer Ausdruck für die Krönungsfeier der Ptolemäer. Zwar

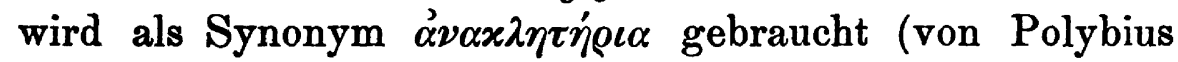
18, 38. 3 bei Gelegenheit der feierlichen Krönung Pt. IV Epiphanes, die am 17. Mechir $=26$. März 195 erfolgte ${ }^{1}$ ) und von der Euergetes II Polyb. 28, 10. 8) aber der solenne Ausdruck dafür scheint $\mathfrak{\varepsilon} \nu \vartheta \varrho$. gewesen zu sein, welches Diod. Sic. 33, 13 von demselben Euergetes II gebraucht ${ }^{2}$ ). Diese Feier fand in Memphis in dem Haupttempel des Reiches statt $^{3}$ ) und wurde mit dem ganzen Pomp der prachtliebenden Lagiden begangen. Eine solche Feier scheint dem Uebersetzer bei der Beschreibung des glänzenden Festes, welches A. im dritten Jahre seiner Regierung gab, vorgeschwebt zu haben, dals sich ihm unwillkürlich für die Wiedergabe der Worte כשבת וגו die Vor-

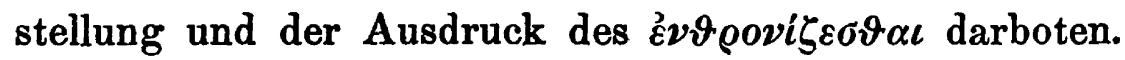

Man wende nicht ein, dafs die Krönung nicht gemeint

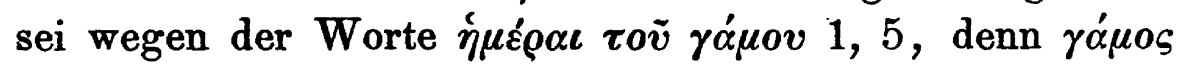
heifst allgemein : Fest vgl. IX, 22, noch, dafs A. ja bereits

1) Letronne recueil des inscr. II. 543 in den Berichtigungen zur Inschrift von Rosette.

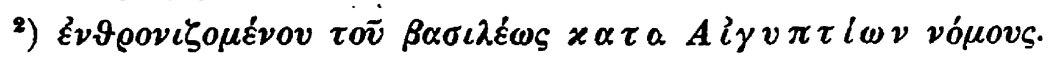

3) Pauly's Realencyclopädie s. v. Memphis. Letronne oeuvres choisis I. II. Par. 1883 p. 561 ff. zitiert Schol. zu Germanic. ed. Buhle p. 71. in templo Aegypti Memphis mos fuit solo regio decorari $(=\varepsilon v$ $\vartheta \varrho o v i \zeta \varepsilon \sigma \vartheta \alpha \iota)$ reges, qui regnabant. 
im dritten Jahre regierte, denn die Krönungsfeier fand stets erst einige Jabre nach der, unmittelbar nach dem Tode des Vorgängers stattfindenden, Uebernahme der Herrschaft

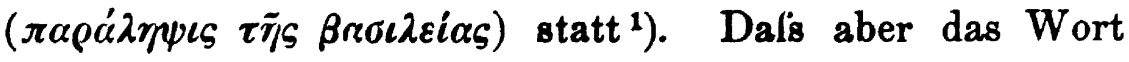
eigens vom Uebersetzer geprägt sei, wird man um so weniger glauben als er überall nur das vulgäre Griechisch spricht und sich nirgends eigene Wortbildungen erlaubt, wie dies andere Uebersetzer der LXX so häufig thun.

Nachmals wurde das Wort geläufig in der kirchlichen Gräzität für die Einsetzung von Bischöfen und anderen Geistlichen und auf diesem Wege und für diesen Begriff auch uns vertraut, daher denn auch in $\mathrm{S}^{2} 64 \mathrm{Compl}$. Ald. die Hand des Klostercopisten zu erkennen sein mag. (Du Cange s. v. thronus, inthronizare.)

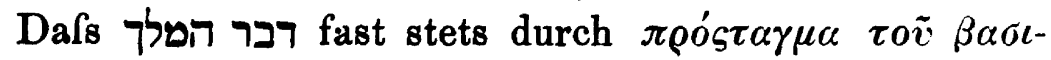
$\lambda \dot{\varepsilon} \omega \varsigma$ oder $\pi \varrho \circ \varsigma \tau \alpha \dot{\alpha} \sigma \sigma \omega$ übersetzt ist, mag auch gemeingriechisch sein; der Ausdruck für Promulgation königרבר המלך ודתו מגיע נת, $\dot{\varepsilon} x \tau \iota \vartheta \varepsilon^{\varepsilon} \boldsymbol{\alpha} \propto \iota$ ist wieder ein speciell ägyptisch-griechisches Wort $^{2}$ ) IV 3. VIII 17. IX $14^{3}$ ). II 23 wird die verdienstliche Handlung Mardechai's in die Annalen des Reiches eingeschrieben : ויכתב בספר דברי הימים לפני המלך.

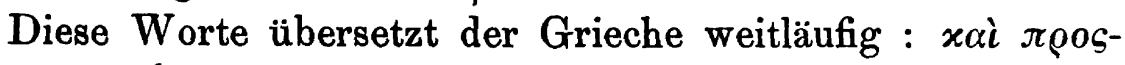

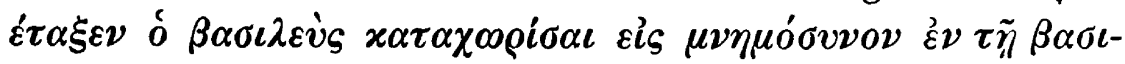


Es sei dahingestellt, ob die beiden letzten Worte ein Glossem sind, jedenfalls ist das Wort $x \alpha \tau \alpha \chi \infty \rho i \zeta \infty$ ein in Aegypten üblich gewesener officieller Terminus für amt-

1) Letronne a. a. O. Champollion-Figeac Annales des Lagides I p. 347. Drumann, die Inschrift von Rosette p. 15.

*) Papiri Greci del Museo brit. di Londra Peyron 1841. II. Zeile 21. 42. 62. 70. III. Zeile 7. Papyrus Grees du Musée du louvre et de la bibl. Imp. in Notices et Extraits v. XVIII. 1865. S. 364.

8) Vgl. an dieser Stelle die Gegenüberstellung von $\varepsilon \pi \iota \tau \rho \varepsilon ́ \pi \varepsilon \iota \nu$ und $\varepsilon x \tau \iota \vartheta \varepsilon \dot{\varepsilon} v u$. 
liche Eintragungen. So schliefst z. B. die bekannte Inschrift von Rosette (Zeile 51) mit der Bestimmung, dafs der vorangehende Beschlufs der vereinigten Priestercollegien in Stein gehauen und eingetragen ( $x \alpha \tau \alpha \chi \omega \rho i \sigma \alpha \iota)$ werde. In den Papyri begegnet uns das Wort sodann häufig ${ }^{1}$ ).

Besonders aber sind Titel und Aemter des persischen Reiches fast durchgängig durch solche des ptolemäischägyptischen wiedergegeben. An zahlreichen Stellen werden die שרים , שרי הטלך durch $9 i \lambda o \iota$ wiedergegeben. Diesen allgemeinen Ehrentitel aber führten in Aegypten die höchsten Beamten des Königs. Freilich nennen griechische Schriftsteller bereits die Beamten des Perserkönigs mit diesem Namen ${ }^{2}$ ), von den Perserkönigen übernahm diese Einrichtung Alexander ${ }^{3}$ ) und von ihm sämmtliche Diadochen ${ }^{4}$ ); besonders oft tritt sie uns aber als ägyptische Titulatur entgegen ${ }^{5}$ ). So finden wir des weiteren fast die gesammte ptolemäische Rangordnung, wie sie am anschaulichsten in einem Turiner Papyrus gegeben wird, wieder.

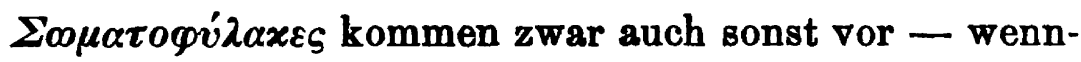
gleich nur in hellenistischen Schriften, deren ägyptischer Ursprung sicher ist $\left.{ }^{6}\right)-$ die $\alpha \varrho \chi(\sigma \omega \mu \alpha \tau \sigma \varphi \dot{v} \lambda \alpha x \varepsilon \varsigma$, die einen so hohen Rang nach Inschriften und Papyri einnehmen, soweit sich ermitteln liefs, nur in dem Aristeas-

') Pap. Brit. VI 43. Notices et Extr. 276. 365. 366. 380. 393. 395. 397. Sturz de dialecto Maccedonica 1808 S. 174 f.

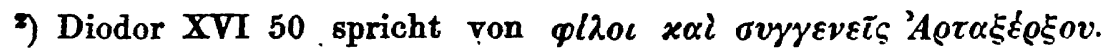
Vgl. die Stellen, die Brisson : de regio apparatu Persarum I 132 zusammenträgt.

8) Arrian VII 11. 10 .

4) für die Seleuciden vgl. z. B. Josephus XIII 4. 4 u. ö. Aber auch am Hofe der Arsaciden und am pontischen findet er sich, vgl. Mommsen : röm. Gesch. V. 343. Anm. 3.

5) C. J. G. III. Introductio p. 289 . Letronne recueil I p. $347 \mathrm{ff}$.

o) Esra apocryphus c. 3. III Macc. II 23. 
brief, welcher, wie Lumbroso ${ }^{1}$ ) eingehend nachgewiesen hat, ganz und gar das ägyptische Vulgärgriechisch spricht, und in unserm Buche II, 21 für שומר ing.

Die Rangklasse der $\left.\delta \iota \alpha^{\alpha} \delta \circ \chi \circ \iota^{2}\right)$, über die wir am wenigsten wissen, glauben wir in $\mathrm{X}, 3$ wiederzufinden, wo

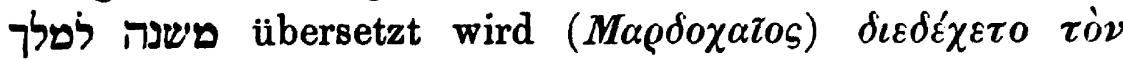
$\beta \alpha \sigma \lambda \varepsilon^{\alpha} \alpha$.



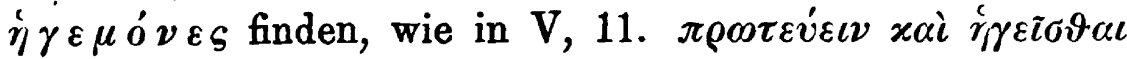
$\tau \tilde{\eta}_{\varsigma} \beta \alpha \sigma i \lambda \varepsilon i \alpha \varsigma$ den Begriff eines $\pi \rho \tilde{o} \tau o \varsigma$ yílos (neben

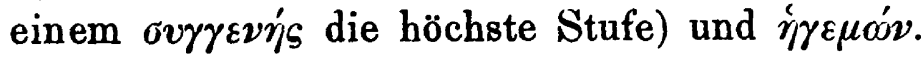

Nicht blofs ein Titel, sondern ein Amt war die Würde eines $\sigma \tau \varrho \alpha \tau \eta \gamma \dot{\sigma} \varsigma$, der bei Aufzählungen von Aemtern an der Spitze steht ${ }^{8}$ ). Wir finden ihn in der Uebersetzung von אחזישרפני המלך III, 12. An einer anderen Stelle (VIII, 9) wird dasselbe Wort durch oixovóno gegeben. Sie müssen eine sehr hohe Würde vorgestellt haben, da man sie stets neben den höchsten Beamten findet $\left.{ }^{4}\right)$. Für $\delta \iota c^{\prime}-$

1) Recherches sur l'économie politique de l'Egypte sous les Lagides Turin 1870 an zahlreichen Stellen dieses Buches.

2) C. J. G. III. Introductio. Papyri Graeci Taurinensis Musei Aegyptii ed. Amadeo Peyron Taur. $1826 / 27$ p. 24. 27. Papyri Graeci Musei Lugduni-Batavi ed. C. Leemans Lugd. 1843. B. Co. $2^{\mathrm{a}}$ v. 13. D. v. 1. E. 1. 2. Pap. Brit. IV 1, sonst II Macc. IV, 29. 31. IX, 23. X, 28 in der LXX besonders oft in der Chronik für ליר I 28. 17. משנדה II 28. 7. שר II 26. 11. Von Joseph gebraucht es Philo de Josepho p. 369. 373. Peyron ist, von wenigen Stellen bei Letronne abgesehen, der einzige, der zur Erklärung der Papyri die LXX zu Rate zieht; unsere Stelle aber ist ihm entgangen.

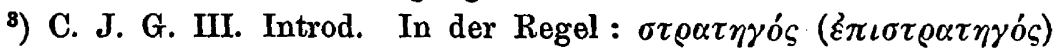
$\varepsilon \pi \tau \sigma \tau \dot{\alpha} \tau \eta \varsigma, \quad \gamma \rho \alpha \mu \mu \alpha \tau \varepsilon \dot{s} \varsigma$.

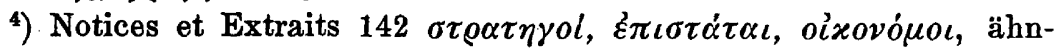
lich 354. 366. 413. Die Bemerkung Letronne's zur letzten Stelle : c'était un intendant du fisc scheint nur auf den oix. $\tau o \tilde{v} \beta \alpha \sigma \iota \lambda \varepsilon^{\prime} \omega \varsigma$ gehn zu sollen, da or fortfährt le nom de ce fonctionnaire ne c'est encore rencontré sur aucun monument grec de l'Égypte excepté dans une inscription de Philes. (Nach einer Ergänzung L's.) Man wird sie 
xovoı = משרתים läfst sich zwar kein Beleg aus Inschriften oder Papyri erbringen, sondern nur eine entfernte Parallele aus dem Aristeasbrief; immerhin ist es bemerkenswert, dafs das hebräische Wort nur im Buche Esther so übersetzt wird I, 10. II, 2. VI, 3. Aehnlich verhält es sich mit den $x \omega \mu \alpha \dot{\alpha} \varrho \chi \alpha \iota=$ פקידים II, 3, welche in allen Provinzen des Reiches bestellt werden sollen, um die schönsten Jungfrauen für den König auszusuchen. Für die klassische Literatur merkt der Thesaurus für dieses Wort nur an Xen. An. IV, 5. X, 2.4. Dionys. IV, 4. Poll. IX, 11 in der Bedeutung Ortsrichter. In der LXX aber findet es sich nur an dieser Stelle. Der Zusammenhang unserer Stelle macht es wahrscheinlich, dafs das Wort auf die Einteilung des ägyptischen Reiches in Nomen, Topen und Komen anspielt. Mag die $x \mu_{\mu} \eta$ eine Unterabteilung des $\tau$ бó ${ }$ os sein oder umgekehrt ${ }^{1}$ ), jedenfalls bezeichnet sie in Aegypten einen Verwaltungsbezirk, und an ihn mag der Uebersetzer gedacht haben. Allerdings nennen die Zeug-

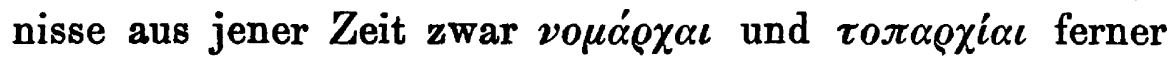

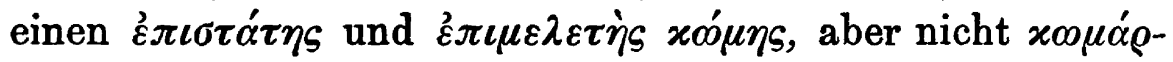
$\chi \alpha \iota$. Daher ist dieses Wort nicht von der Beweiskraft der anderen, wenn auch nichts natürlicher zu sein scheint, als



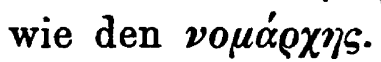

Mehr als ein blofser Anklang ist die Uebersetzung

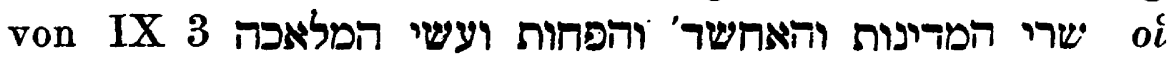


$x \circ i \gamma \rho \alpha \mu \mu \alpha \tau \varepsilon i \bar{c}$.

Bevor man ägyptische Verwaltung unter den Ptolemäern kennen gelernt hat, wundert man sich, unter den höchsten Staatswürdenträgern : „königliche Schreiber ${ }^{\text {“ zu }}$

aber auf den oix. schlechthin ausdehnen können, wenn man sieht, dafs dars er stets dem $\beta \alpha \sigma i \lambda \iota x o$ s y $\rho \alpha \mu \mu \alpha \tau \varepsilon \dot{v}_{\zeta}$ vorangeht.

1) Droysen : Gesch. d. Hellenismus 2. Aufl. 1877. III 41. Anm. 1. 
finden. Aber zahlreiche Stellen in Inschriften und Papyri ${ }^{1}$ ) lehren uns, dafs mit diesem Namen die höchsten Steuerbeamten des ägyptischen Reiches bezeichnet wurden. Sie waren die Vorgesetzten der $\tau о л о \gamma \rho \alpha \mu \mu \alpha \tau \varepsilon \tilde{I}_{\zeta}$, deren es in

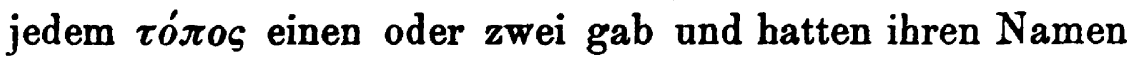
wahrscheinlich von der Führung der Steuerlisten. Also es sind so wenig "Schreiber" wie bei uns ein "Staatssekretär."

Wie ausgedehnt überhaupt das schriftliche Verfahren bei den Aegyptern der letzten vorchristlichen Jahrhunderte war, das lehren in der anschaulichsten Weise die im Vorstehenden so oft genannten Papyri. Wie viel Schreibereien kostet es z. B. jene armen Schwestern, ehe sie ihr Deputat an Brot und Oel erlangen können $\left.{ }^{2}\right)$ ! Wie viel schriftliche Beschwerden, Rescripte, Appellationen, Verfügungen! Für diesen vielschreibenden Büreaukratismus ist es bezeichnend, dafs zahlreiche Ausdrücke für gerichtliche und finanzielle Handlungen, Actenstücke, Funktionäre durch Ableitungen von $\gamma \rho \alpha \dot{\varphi} \varphi \varepsilon \iota \nu$ gebildet werden. Eine solche begegnet uns

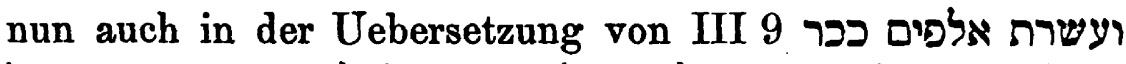

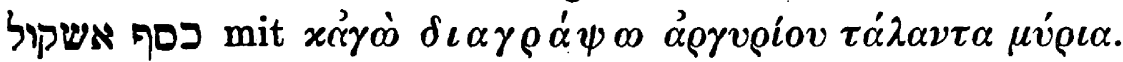

Dieses Verbum kommt zwar in den verschiedensten Bedeutungen vor, nirgends aber in der unserer Stelle : ,aus eigener Tasche zahlen." ${ }^{*}$ Peyron ${ }^{3}$ ) gab zwar im Jahre 1826 eine für damals erschöpfende Darstellung der Begriffe

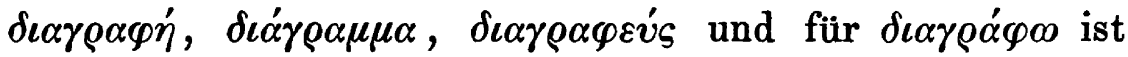
ihm unsere Stelle und II Macc. IV, 9 nicht entgangen, aber erst der Papyrus der Zois lehrt es uns als ein im ägyptischen Geschäftsverkehr ganz gewöhnliches Wort für "bezahlen" kennen und seitdem treffen wir es häufig ${ }^{4}$ ).

1) z. B. Notices et Extr. 142. 354. 366.

2) In der Sammlung Leydener Papyri von Leemans.

3) Pap. Taur. I 115.

4) Papiri greco-egizi v. Petrettini 1828 und Letronne in der Recension dieses Werks in Journal des savans 1828 p. 477 und oeuvres 
Es kommen in der Uebersetzung noch manche Wörter vor, die vorwiegend dem ägyptischen Dialekt des Griechischen anzugehören scheinen z. B. : $\sigma v \nu \tau \varepsilon \lambda \varepsilon \tilde{\varepsilon} v=$ thun IV 1 , vgl. Inschrift von Rosette Z. 40. 48. 52; $\pi \alpha \varrho \alpha \gamma i v \varepsilon \sigma \vartheta \alpha \iota=$ kommen V 5, vgl. ebend. und Aristeas 29, 7. 43, 17. 44, 22. 45, 15. 18. 62,10 u. ö. (nur S. 43 wird mit "ै $\varrho \chi \varepsilon \sigma \vartheta \alpha \iota$,

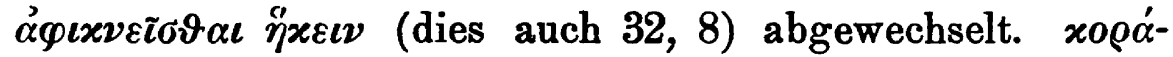

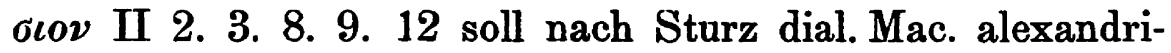
nisch sein. IX 29 heifst es M. und Esther schreiben auf

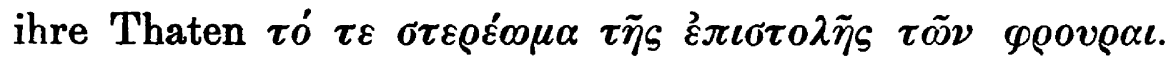

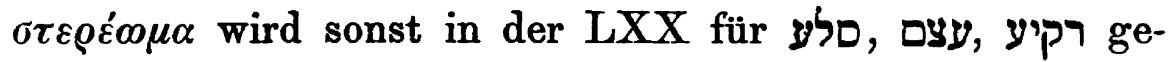
setzt, aber an unserer Stelle scheint etwas ähnliches damit gemeint zu sein, wie am Schlufs der Rosette-Inschrift : $\tau \grave{o}$

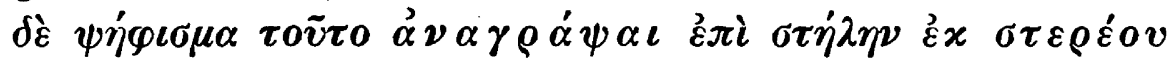
$\lambda i \vartheta o v$. Jedoch: diese Ausdrücke sind entweder unsicher oder sie gehören der xoıv gestellten und für die Uebersetzung von zehn meist kurzen Kapiteln immerhin zahlreichen Aegyptiacismen : ( $(\dot{\varepsilon} v) \vartheta(00-$

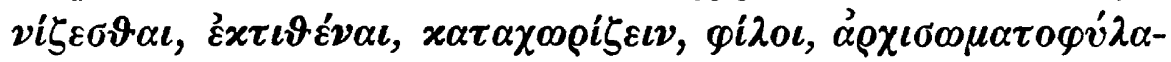

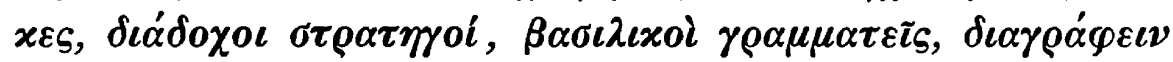
reichen aus, um die Angabe der Nachschrift nicht nur zu widerlegen, sie beweisen auch mit Gewifsheit, dafs die Uebersetzung nur in Aegypten verfertigt sein kann. Sie berauben die ganze Unterschrift endgültig jeder Glaubwürdigkeit, und wir müssen daher unabhängig von ihr auch die Zeit zu bestimmen versuchen, in der die Uebersetzung entstanden sein mag.

Soviel darf man von vornherein entscheiden, dafs der Uebersetzer noch in den Zeiten der Ptolemäerherrschaft


$\alpha \dot{v} \tau \tilde{\eta} \varsigma-\mu \dot{\eta} \tau \varepsilon \tau \sigma \tilde{\imath} \Delta \omega \rho l \omega \nu o \varsigma$ (des Schuldners) $\delta \iota \alpha \gamma \rho \alpha \psi \dot{\alpha} \alpha \nu \tau \sigma \varsigma \mu \dot{\eta} \tau \varepsilon$





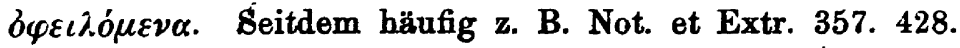


gelebt haben mufs, in jener Zeit, da noch das gesamte umständliche Hofceremoniell mit seinen Titeln, Würden und Chargen in voller Blüte stand. Denn ob auch im ganzen das römische Regiment einfach die Fortsetzung der griechischen Herrschaft wurde, $n^{80} \mathrm{kam}$ in dem neuen Regiment vor allem in Betracht die Unterdrückung des Hofes und der Residenz, die notwendige Folge der Einziehung des Landes durch Augustus. Der blofse Wechsel der Dynastie wäre nicht allzusehr ins Gewicht gefallen. Aber ein Hof wie der der Ptolemäer, geordnet nach dem Ceremoniell der Pharaonen, König und Königin in ihrer Göttertracht, der Pomp der Festzüge, der Empfang der Priesterschaften, die großsen Ceremonien der Krönung, die Hofämter der Leibwächter und des Oberleibwächters $(\alpha \varrho \chi \iota \sigma \omega \mu \alpha \tau o \varphi \dot{v} \lambda \alpha \xi)$..... die Vettern und Freunde des Königs, die Decorirten - das alles ging für die Alexandriner ein für allemal unter mit der Verlegung des Herrschersitzes vom $\mathrm{Nil}$ an die $\mathrm{Tiber}^{* 1}$ ). Da nun die Sprache der Uebersetzung jene Zeit und besonders ihre höfischen Einrichtungen unverkennbar noch als gegenwärtig spiegelt und aus eigener Kenntnis und Anschauung in Worten und Wendungen unwillkürlich wiedergiebt, so haben wir das Recht, als den spätesten Zeitpunkt das Jahr 30 a. Ch. anzusetzen. Denn in diesem Jahre endete mit dem selbstgewählten Tode der letzten Fürstin des Lagidenhauses dieses durch die Gräuel und Schandthaten der Bruderzwiste, Gatten- und Kindermorde fluchbeladene Geschlecht, und das Land der Pyramiden wurde die erste der Provinzen des neuen römischen Kaiserreichs.

Mehr kann man mit Sicherheit nicht aussagen. Aber mit einem gewissen Grade von Wahrscheinlichkeit könnte man vielleicht noch ein volles Jahrhundert höher hinaufgehn. Einer der wenigen festen Punkte für die Zeitbestimmung

1) Mommsen, Röm. Gesch. V, S. 564. 566. 
der LXX ist bekanntlich die Vorrede zur Uebersetzung des Siraciden. Dort sagt der Uebersetzer, er sei im 38. Jahre

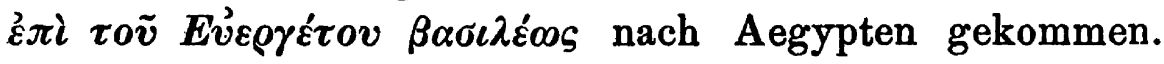
Er entschuldigt die Mängel seiner Arbeit mit der Verschiedenheit der Ursprache und einer andern - welche nur die griechische sein kann. Dies erhelle auch aus den Uebersetzungen des Gesetzes, der Propheten und übrigen Schriften : תורה נביאים וכתובים. Demnach müssen im 38. Jahre des Euergetes ${ }^{1}$ ) d. i., da nur Euergetes Physcon länger als 38 Jahre regierte, im Jahre 132 bereits mehrere nichtpentateuchische Bücher übersetzt gewesen sein. Nun hat Freudenthal ${ }^{2}$ ) des besondern nachgewiesen, dafs um die Mitte des zweiten vorchristlichen Jahrhunderts bereits die Uebersetzungen der Königsbücher, der Chronik, des Hiob und wahrscheinlich auch Josua vorhanden waren. Denn überall, wo in den hellenistischen Schriften jener Zeit, deren Fragmente aus Alexander Polyhistor durch Eusebius erhalten sind, der Text der Siebenzig zu tage tritt, steht er dem heute uns vorliegenden überaus nahe. Wenn nun jene biblischen Bücher damals bereits in griechischer Uebersetzung vorlagen, so kann man es auch vom Buche Esther annehmen. Denn ohne in die Controverse darüber einzutreten, ob die Uebersetzung des Pentateuch ihr Entstehen dem literarischen Wunsch eines Ptolemäers, sei es Philadelphus oder Philometor, oder einem praktischreligiösen Bedürfnis der griechisch-redenden Judenheit verdanke, für kaum ein anderes nicht-pentateuchisches Buch darf man die letzte Auffassung mit solcher Wahrscheinlichkeit in Anspruch nehmen, wie für das Buch E. Dafs das Purimfest selbst allgemein gefeiert wurde, ist ja selbst

1) Denn es wird nunmehr allgemein zugegeben, dafs nur das 38. Jahr des Energetes, nicht das 38. Lebensjahr des Schreibers gemeint sein könne.

2) Hellenistische Studien 185. 
ohne die Nachricht 2 Macc. XV, 36 von vornherein anzunehmen, und wenn uns auch für die Art und Weise, wie der Gottesdienst an diesem Tage eingerichtet war, jede Spur fehlt, so wird die Verlesung des Estherbuches jedenfalls dazu gehört haben. Mufste sich doch gerade dieses Büchlein wegen seines geringen Umfanges zu ungekürzter Mittheilung empfehlen. Es war das wirksamste Mittel, der versammelten Gemeinde die Bedeutung des Tages in lebendiger Erinnerung zu erhalten. Daraus ergiebt sich aber, dafs das Bedürfnis, gerade dieses Buch ins Griechische zu übersetzen, alsbald nach dem Schwinden der Kenntnis des Hebräischen eingetreten sein wird. Ja man könnte es hiernach als das erste Buch nach dem Pentateuch setzen, mag selbst der Gebrauch der Haphtarah, der Verlesung eines Prophetenabschnitts nach der Pentateuchperikope oder an deren Stelle ein bis in jene Zeiten hinaufreichendes Analogon in den Proseuchen der Diaspora gehabt haben oder auch einzelne Psalmen zu gottesdienstlichem Gebrauch übersetzt worden sein.

Wenn man auf solche Vermutungen hin sich entschliefsen könnte, die Uebersetzung noch vor das Jahr 132 a. Chr. zu setzen, so würde sich diese Annahme selbst mit den spätesten Datierungen des hebräischen Buches vertragen. Denn eine grofse Anzahl Gelehrter setzt dieses ja in die Zeit vor dem Aufstand unter Antiochus Epiphanes oder während desselben und sieht darin einen Reflex des Nationalhasses oder eine griechenfeindliche Tendenzschrift ${ }^{1}$ ).

Aber an den zwei Thatsachen dürfen wir festhalten : Die Uebersetzung ist in Aegypten verfafst und zwar vor dem Jahre 30 a. Chr.



1) Bertholdt, Zunz, Kuenen, Bloch, Reufs, Grätz (Monatsschrift 1886), vgl. die Bücher Esra, Nehemia, Esther erklärt von BertheauRyssel $^{2} 1887$ S. $369-375$. 


\section{IV.}

\section{Erweiterungen.}

Nachdem einmal das Buch übersetzt worden war, blieb es das Eigentum des hellenistischen Judentums. Deutung und Erklärung gingen ihre eigene Wege, nicht immer glücklich allerdings. Eine der auffallendsten Eigentümlichkeiten dieses Buches der Bibel ist es bekanntlich, dafs darin auch nicht ein einziges Mal der Name Gottes vorkommt. Welches auch immer der Grund für dieses seltsame Schweigen sein mag, sicherlich ist es beabsichtigt. Das griechische Buch aber setzt an mehreren Stellen ${ }^{1}$ ) ohne Bedenken und wie es allen Anschein hat ohne Bewufstsein von jener Thatsache das Wort Gott : ףとós. Die

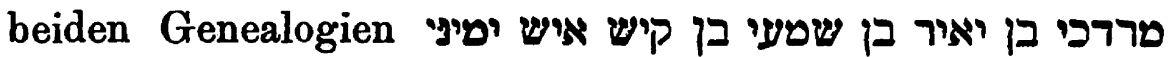
und המן בן המרתא האנגי werden von der gesammten palästinensisch-hagadischen Auslegung, der in diesem Falle auch Josephus folgt, dahin aufgefalst, dafs die Feindschaft der beiden Gegner in dem Volkshafs zwischen Israel und Amalek begründet ist. Sie soll in jene Zeit hinaufgeführt werden, da Agag, der König der Amalekiter, von Saul, dem Sohne Kischs besiegt, gefangen genommen, dann von Samuel in Stücke gehauen ward zu Gilgal ${ }^{2}$ ). Von dieser, im Midrasch allgemeinen Auffassung bietet das griechische Buch keine Spur. Das beweist, dafs es selbständig begriffen und gedeutet wurde.

In welch ausgebreitetem Mafse die erzählenden Bestandteile der Bibel selbständig bearbeitet wurden, dafür zeugt die ganze hellenistische Literatur von Eupolemos bis hinab zu dem umfassenden Werke des Josephus : der jüdischen Archäologie in den ersten elf Büchern. Das Interesse der Abwehr gegen feindliche Angriffe, der Ausglei-

1) VI, 1. 13.

) 1 Sam. 15. 8. 33 . 
chung mit abweichenden heidnischen Darstellungen, der fromme und patriotische Eifer, dem auf eine reiche, glänzende Geschichte und Literatur mit Recht stolzen Hellenentum eine nicht minder rühmliche, wenn möglich ältere, ursprünglichere Vergangenheit zu entrollen, riefen dieses Schrifttum ins Leben. Nicht zufrieden mit den einfachen Berichten der heil. Schrift, versetzten sie dieselben mit den mannigfaltigsten Bildungen entlehnter Sage, frei erfundener Dichtung. Not, Begeisterung und die Lust zu fabulieren waren die Wurzeln dieses oft in phantastischen Formen um den Stamm der biblischen Berichte wuchernden Gestrüpps. Das willkommenste Feld boten die älteste Geschichte von der Weltschöpfung bis Moses und dann wieder die glänzende Zeit Salomos, weil in diesen, umbequemer Controlle entrückten, zum teil vor jeder profanen Geschichte liegenden Zeit die Phantasie sich am ungebundensten ergehen konnte. Daher beschäftigt sich denn auch der gröfste Teil jüdisch-hellenistischer vermeintlicher Geschichtsschreibung mit den Gestalten aus jener Zeit. Dafs aber auch spätere Abschnitte, das Exil und die folgenden Jahrhunderte, der Lust zu erzählen und zu erdichten, nicht entgangen sind, dafür bürgen freilich weniger Zeugnisse; auch mufste man bei dem geringen Abstande von der Gegenwart vorsichtiger auftreten, $\mathrm{Zu}$ sammenstöfse mit der verbürgten und bekannten Geschichte vermeiden und sich daher auf Ausmalung einzelner Züge beschränken; man mulste mehr in die Tiefe als in die Breite gehn. Wenige Teile der Schrift mochten diesem Streben willkommener sein als die Erzählung von der Not und Befreiung des jüdischen Volkes unter einem persischen König, von der Erhebung einer jüdischen Jungfrau auf den Thron eines mächtigen ungeheuren Reiches, von der Feindschaft zwischen dem Juden Mardechai und dem Heiden Haman, von dem schmählichen Sturz und Ende des Verfolgers. Daher ist unser Buch in 
der palästinensischen Hagadah die Quelle eines so mächtig angeschwollenen Stromes von Sage und Dichtung geworden, wie kein anderes. So ist denn auch das hellenistische Judentum nicht bei der Uebersetzung stehen geblieben. Fordern doch manche Momente gradezu zur Ergänzung heraus. Wie mochten die Schreiben, wie die Gebete gelautet haben, die nur angedeutet werden? Die Person Mardechai's, sein Verhältnis zu Haman, die Lebensführung Esthers an dem heidnischen Hofe und vieles andere forderten die Wifsbegier und somit apocryphe Schriftstellerei heraus. Ohne $\mathrm{Z}_{w}$ eifel wird die Geschichte Esthers ebensowohl ihre eigene romanhafte Bearbeitung gefunden haben, wie das Leben Abrahams, Jacobs, Josephs, Moses. Als einen Niederschlag solcher Bearbeitungen betrachten wir die sogenannten Zusätze, die zum teil palästinensischhagadischer, zum teil hellenistischer Natur sind. Bevor wir jedoch an ihre Betrachtung gehen, sind mehrere kleine Züge aufzuzählen,' die in unsern Text eingedrungen sind und einen reicheren Hintergrund ahnen lassen.

Zu den goldenen Gefärsen, die bei dem Gastmahl am Anfang der Erzählung erwähnt werden, fügt unsere Ueber-



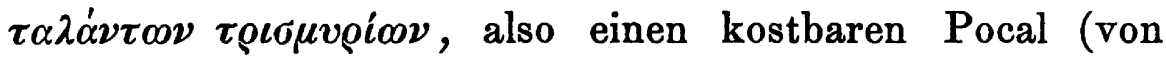
Karfunkelstein?) im Werte von 30000 Talenten. Dieser Zusatz hat weder im Text einen Anhalt, noch im Midrasch eine Parallele. Er ist ein Zug aus einer Ausmalung des Gastmahls. Die Wertangabe erregt allerdings Bedenken; denn 30000 Talente wären die ungeheure Summe von 115 Millionen Mark, das doppelte der Jahreseinnahme der Ptolemäer in ihrer glänzendsten Periode, wo es 14800 Silbertalente betrug ${ }^{1}$ ). Und Aegypten hatte von allen Ländern der alten Welt die glänzendsten und geordnetsten Finanzen. Vielleicht ist daher zu lesen $\alpha \dot{\pi} \boldsymbol{j}, \Gamma \tau \alpha \lambda \dot{\alpha} \nu \tau \omega \nu$

1) Mommsen, Röm. Gesch. V, 560.

Zeitschrift f. d. alttest. Wiss. Jabrgang 10. 1890. 
anstatt $\alpha^{\prime} \pi \dot{o} \Gamma^{\prime}$ (d. i. 30 Talente). Diesen immerhin noch beträchtlichen Wert hat auch der Becher, den der König Philadelphus, welchen Aristeas gewifs nicht geizen läfst, dem Hohenpriester Eleazar sendet.

Ein anderer kleiner Zusatz sind die Worte, in die Mardechai IV, 1 ausbricht al' deren hohes Alter Josephus (XI, 6. 7) bezeugt : $\mu \eta \delta \dot{\nu} \nu$

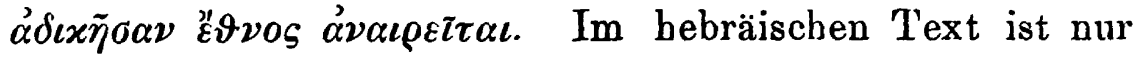
von einer lauten, bittern Klage, die M. ausstö/st, die Rede, ohne dafs ihr Wortlaut gegeben würde. Ob nicht auch dieser abgerissene Satz das Bruchstück einer längeren Klage ist? Eine fernere Ausschmückung ist die Angabe, dafs die Hochzeit des Königs mit Esther sieben Tage gedauert habe (II, 8).

Der einem jüdischen Leser sich aufdrängenden Frage, wie E., die Nichte M.'s, an dem heidnischen Hofe gelebt habe, kommt bereits II, 20 ein Zusatz zuvor : M. habe ihr

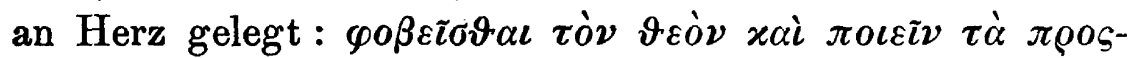



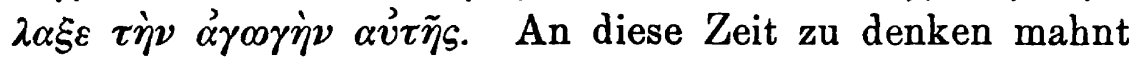
sie später (IV, 8) M.

V, 4 begründet E. ihre Einladung mit den Worten

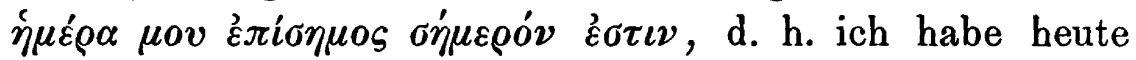
einen (oder meinen) Feiertag ${ }^{1}$ ). Auch dieser $\mathrm{Zug}$ ist sagenhaft und es scheint hier wieder eine Darstellung durchzublicken, welche das Leben E.'s an dem Königshofe zu Susa eingehender behandelte.

Dies sind zunächst nur wenige Zeichen und Züge romanhafter Bearbeitung oder, wenn man will, des hellenistischen Midrasch Esther. Dafs uns aber in dem Buche nicht alles erhalten ist, was in dasselbe hineingedichtet

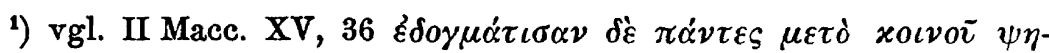

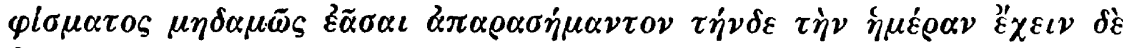
$\varepsilon \pi i \sigma \eta \mu o v$. 
wurde, zeigt die Darstellung bei Josephus. Zwar ist hier schwer zu entscheiden, was palästinensischer Hagadah angehört, was er selbst hinzugethan und was ursprünglich hellenistisch ist. Wenn uns aber Freudenthal belehrt : „dafs es dem sonst hervortretenden Charakter der Josephischen Darstellung nicht entspricht, neue Züge frei zu erdichten ${ }^{(1)}$ ) und man vermuten darf : „dafs er gerade da, wo er scheinbar am freiesten dichtet, älteren Quellen am treuesten ist ${ }^{(2)}$ ), so darf man alles das, was dem Midrasch fremd ist oder was ihn nicht der Pragmatismus der Erzählung sagen zu lassen braucht, hellenistischen Quellen zuweisen. Daher verzichten wir auf folgende Züge : dafs unter dem Prachtzelte Myriaden lagern konnten, dafs bei den Persern Fremde kein Weib anblicken durften ${ }^{3}$ ), dafs der König bei der Weigerung Vasthis das Mahl aufgehoben habe, dafs Mard. einer der ersten unter den Juden gewesen ${ }^{4}$ ), Est. aus königlichem Geschlecht ${ }^{5}$ ), dafs Henker zu sofortigem Vollzug der Todesstrafe den Thron umstanden, so jemand ungerufen vor dem Angesicht des Königs erschien, dafs die Feindschaft Hamans gegen Mard. aus einem National-Antagonismus von den Zeiten Saul's her rühre ${ }^{6}$ ), M.'s Antwort an E., er könne das Trauergewand nicht ablegen, bevor die Veranlassung zur Trauer aufgehört habe, die Szene der Vorlesung vor dem König ${ }^{7}$ ), die Reflexion über Hamans Schicksal. Es bleibt immerhin noch manches, das Jos. nur hellenistischer Darstellung der Esthergeschichte entnommen haben kann, ohne dafs es

1) Studien 176 in der hierfür besonders lehrreichen Vergleichung des Moses-Romans bei Artapanos und Jos.

2) ebend. 187.

8) äbnlich Targum I u. II z. St.

4) Targum und Midrasch z. II, 5.

5) ebendort.

6) Targum I z. III, 6.

7) Targum I z. VI, 1. 
seinen Weg in die griechische Uebersetzung des Buches gefunden hat.

So erzählt er, dafs die Zahl der im Harem des Königs vereinigten Jungfrauen 400 betragen habe. Schwerlich hat Josephus sie erfunden. Vielleicht liegt dieser Zahl ebenso wie der Aenderung $A \delta a \rho$ II, 16 für טבת eine Berechnung der I, 3. II, 12. II, 16. III, 7 gemachten Zeitangaben zu grunde, die wir jedoch nicht mehr verfolgen können.

Eine ähnliche Bewandtnis mag es mit der Summe von 4000 Talenten $=10000$ Kikar haben. Dafs nach Josephus Esther aus Babylon geholt und von ihrem Oheim nach Susa begleitet wurde, mag ein Mifsverständnifs von II, 6 sein, ganz bestimmt aber verrät hellenistischen Ursprung die Nachricht, dafs Mard. von der Verschwörung der beiden Palastwächter durch den jüdischen Sclaven des einen

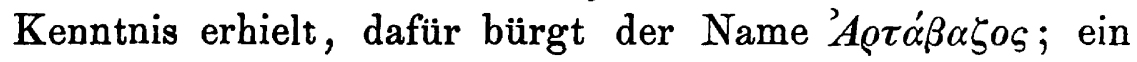
persischer Name ist gewählt, weil Persien das Land der Handlung ist.

Ueberhaupt hat die Erzählung von der Verschwörung der beiden Wächter eine durchgreifende Veränderung erfahren, welche sich darin zeigt, dafs die Uebersetzung von II, 21-23 verstümmelt und eine andere Darstellung an den Beginn der Erzählung gesetzt ist und zwar an das Ende des ersten grölseren Zusatzes v. 11-18. Somit sind aus der einen zwei Verschwörungen geworden, die eine im zweiten Jahre des Königs A., die andere im siebenten. Lucian hat nur den Zusatz am Anfang des Buches, dagegen lälst er die zweite Verschwörung d. i. II, 21-23 fort, in dem richtigen Gefühl, dafs nur eine überflüssige Wiederholung und selbst ein Widerspruch vorliege. Wir können jedoch noch mit Bestimmtheit nachweisen, was hier vorgegangen ist.

Josephus, der nur Text $\beta$ vor sich haben konnte, spricht nur von einer Verschwörung. Die Verschworenen 



kommen in der Uebersetzung II, 21 gar nicht vor, sondern



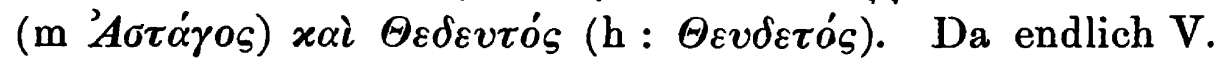
den Zusatz überhaupt nicht, die Uebersetzung II, 21-23 aber unverkürzt und darin die Namen Bartagaeus ( $O$ : Bastagaeus) et Thedestes hat, so ergiebt sich : In der Erzählung der Verschwörung folgte ursprünglich die Uebersetzung dem hebräischen Text II, 21-23 und las hier die

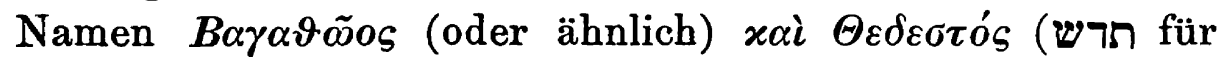
שר). Diesen Bestand fand nicht nur Josephus, sondern auch noch die vetus latina vor. Später wurde nun an den Anfang des Buches ein bereits früher geplantes Attentat gestellt. Seine Vereitelung durch Mard. erweckte den Zorn Hamans, des Gönners der beiden Verbrecher, der deswegen $M$. und sein Volk vernichten wollte. Da sich nun hiernach II, 21-23 als eine offenbare Wiederholung kund gab, versuchte man die Bedenken dadurch zu heben, dafs man die Namen fortliefs und als Ursache für den

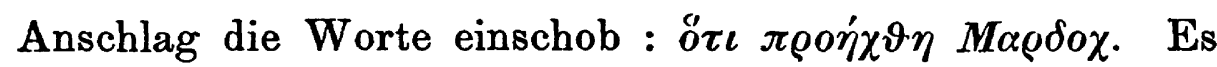
bleibt freilich trotz alledem ein Widerspruch, wie M. schon im zweiten Jahre des Königs eine Verschwörung an dessen Hofe anzeigen kann, da er doch erst im siebenten mit der Erwählung Esthers dorthin kam. Die Hand nun, welche diese Verwirrung angestiftet hat, kann ihr Ungeschick nicht vor der Mitte des zweiten nachchristlichen Jahrhunderts bewiesen haben, da der Lateiner von ihr noch unberührt ist. Man mufs aber vielleicht noch ein Jahrhundert tiefer gehn, da dem Interpolator bereits ein hexaplarischer Text vorgelegen zu haben scheint. Wie käme er sonst zu den Namen $\Gamma \alpha \beta \alpha \vartheta \alpha$ xai $\Theta \alpha \rho \varrho \alpha$ ? Schwerlich nahm er sie unmittelbar aus dem Hebräischen בגתן ותרש.

Die Frage nach der Ursprache des Stückes Addit. I, 11-18 kann demnach gar nicht erhoben werden, da es nur eine dürftige Umschreibung von $I$, 21-23 ist. Ein 
jüdischer Verfasser hätte auch gewifs nicht solche offenbaren Widersprüche geschaffen. Dies beweist am besten Josippon ben Gorion, der einzige in der jüdischen Ueberlieferung, der dieses Stück aufgenommen hat. Denn obgleich er offenbar die griechische Quelle verrät, bringt er doch alles in glücklichen Einklang ${ }^{1}$ ).

In dem Text ist für $\alpha \dot{\alpha} \eta \chi \vartheta \eta \sigma \alpha \nu$ vielleicht mit Compl. $\alpha^{\prime} \pi \dot{\eta} \gamma \chi \vartheta \eta \sigma \alpha \nu$ zu lesen. Am Schlufs mufs man aus $\alpha$ die

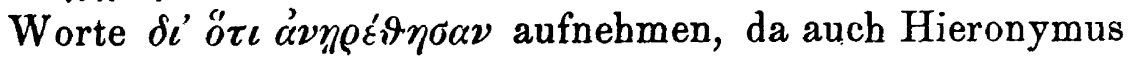
übersetzt qui fuerant interfecti. $H$. aber übersetzt in den Stücken stets nur $\beta$.

In $\alpha$ ist doch wohl mit Kreilsig für $\dot{\varepsilon} \pi \iota \varphi \alpha \nu \tilde{o} \varsigma$ zu lesen

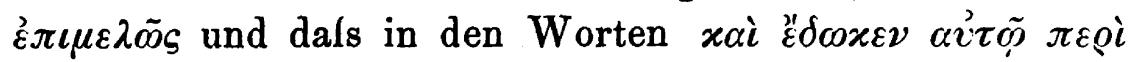


durch ein falscher Casus entstanden sei, sieht man leicht.

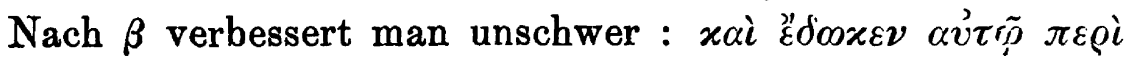

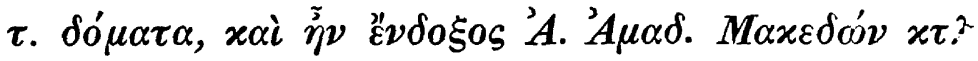

Erst nach Erledigung dieser kleineren Erweiterungen, Einschübe, Aenderungen könnten wir an die Betrachtung der umfangreicheren Interpolationen gehn, der eigentlich so genannten : „Zusätze zu Esther“ oder „Stücke in Esther."

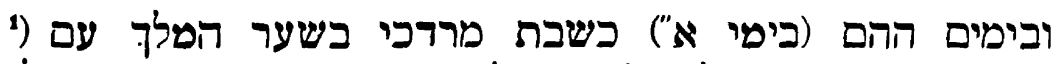

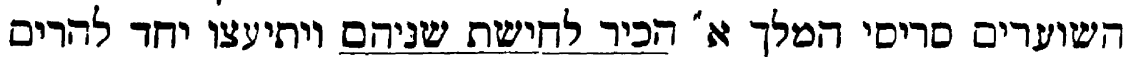



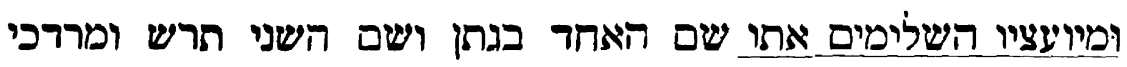

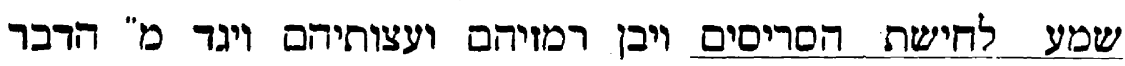

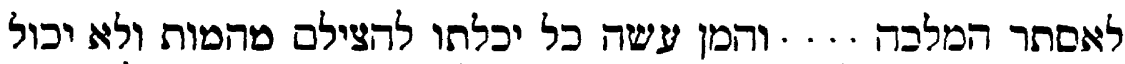

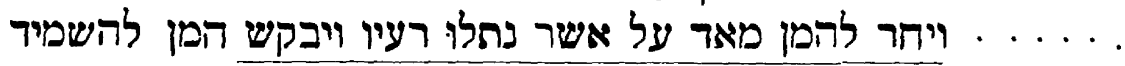

פ כל דיחורים zweiten Jahre hatte. 